\title{
Noticias de la biblioteca de un ilustrado gaditano: don Guillermo Tirry y Tirry, III marqués de la Cañada
}

Sara Cosano Laguna

Universidad de Sevilla

CES.XVIII, núm. 21 (2011), págs. 59-92. 
Resumen: En el siglo XVIII Cádiz fue una de las ciudades españolas más prolificas en cuanto a la producción de libros y a la creación de grandes bibliotecas privadas, un esplendor que también alcanzó a su provincia. De hecho, Jerez de la Frontera y El Puerto de Santa María constituyeron igualmente sendos núcleos de irradiación e intercambios librescos. El presente trabajo es un acercamiento a la biblioteca particular de Guillermo Tirry y Tirry, III marqués de la Cañada, el bibliófilo más relevante de su época en El Puerto de Santa María. Ofrecemos las primeras noticias de las obras que tuvo el marqués basándonos en diversas fuentes, entre las cuales destaca especialmente un manuscrito inédito del Archivo Municipal de Sevilla que obraba en poder del II conde del Águila. Asimismo, hacemos referencia al proceso de formación de su biblioteca. El artículo se completa con las fichas catalográficas de aquellos libros de los que contamos con una referencia documental constatable.

Palabras clave: Guillermo Tirry y Tirry. Marqués de la Cañada. Bibliotecas. Archivo Municipal de Sevilla. Conde del Águila. 
Hace apenas diez años, Manuel Ravina llamó la atención sobre un reducido grupo de comerciantes y aristócratas gaditanos que poseyeron grandes bibliotecas particulares en el siglo XVIII, pero de las que no ha quedado ninguna constancia documental. La carencia de inventarios de estas colecciones contrastaba con las fuentes conservadas de los fondos de las bibliotecas eclesiásticas y de las nuevas instituciones surgidas a lo largo del siglo ilustrado․ Señalaba igualmente que aquella pequeña élite intelectual mostraba un interés inusitado por la bibliofilia y sentía una especial predilección por el arte; eran políglotas y habían podido viajar por el extranjero gracias al gran caudal de sus fortunas. En El Puerto de Santa María destacó la célebre personalidad del III marqués de la Cañada, Guillermo Tirry y Tirry, que seguramente tuvo contacto con ese circuito cultural de la capital por compartir, como veremos, las mismas aficiones literarias y tener unas afinidades artísticas comunes. En general, el conocimiento del mundo del libro y de las bibliotecas privadas portuenses en el siglo XVIII es aún muy parco, por eso el feliz hallazgo del listado incompleto de la venta de los libros del marqués de la Cañada resulta de gran utilidad para esbozar el perfil intelectual de don Guillermo Tirry y Tirry.

\section{Antecedentes familiares y apuntes biográficos}

Desde sus orígenes, el linaje irlandés de los Tirry estuvo vinculado al comercio ${ }^{2}$. Ávido de prosperidad económica y medro social, uno de sus miembros, Guillermo Tirry (1663-1745), no dudó en arribar a El Puerto de Santa María a finales del siglo XVII, cuando la bahía gaditana atravesaba su época de máximo esplendor. Esta bonanza, unida a su perspicacia para los negocios, hizo que

1 Vid. Manuel Ravina Martín, «El mundo del libro en el Cádiz de la Ilustración», Cuadernos de Ilustración y Romanticismo, 9 (2001), págs. 89-102. Los trabajos más recientes sobre bibliotecas ilustradas del ámbito gaditano están centrados en estos dos campos de estudio. Vid. Rosario Martínez López, La Biblioteca de la Academia Provincial de Bellas Artes de Cádiz, Cádiz, Diputación Provincial, 2001, 2 vols.; Frédérique Morand, «La biblioteca de la poetisa gaditana sóror María Gertrudis de la Cruz Hore (1742-1801)», Cuadernos de Estudios del Siglo XVIII, 17 (2007), págs. 249-274.

2 Kevin Terry, Terrys of Cork 1600-2000: A local Historical Perspective, Midleton, Litho Press, 2005. Aunque a veces hayan sido nominados también como Terry, hemos optado por utilizar la variante más frecuente con la que aparecen registrados en la documentación notarial: «Tirry». 
Guillermo figurase muy pronto entre una poderosa oligarquía de base agraria y mercantil ${ }^{3}$. Los cuantiosos beneficios económicos reportados por su actividad agilizaron sin duda los trámites para la fundación de su mayorazgo en 1721. Con ello perseguía un doble objetivo: perpetuar su solvente posición social en pos de alcanzar el poder político. Como señala Lidia Anes, estas estrategias fueron muy comunes entre la burguesía enriquecida ${ }^{4}$. Para conseguir su primera meta y evitar la dispersión de su capital, casó en 1723 a Francisca Patricia, su única heredera, con su sobrino Juan Tirry. No obstante, el cenit de su carrera llegó el 12 de agosto de 1729, cuando Felipe V le concedió el título de marqués de la Cañada ${ }^{5}$. Dos años después, cuando el rey puso a la venta los veintiún cargos concejiles de El Puerto de Santa María, adquirió una de las regidurías a principios de junio, que al poco sería vendida a don Pablo Luis Quijada para comprar, por 60.000 reales $^{6}$, el empleo de alférez mayor con voto perpetuo ${ }^{7}$ a mediados de agosto del mismo año. Juan Tirry y Francisca Patricia Tirry tuvieron dos hijos, Rosalía Isabel y Guillermo, sobre quien recayó el marquesado tras la muerte de su madre en 1759, al mismo tiempo que heredaba el mayorazgo fundado por su abuelo. La administración del mayorazgo le sobrevino cuando ya había desempeñado otros cargos de responsabilidad.

Don Guillermo Tirry y Tirry (1726-1779) llegó a ser gentilhombre de Cámara del rey, aunque en la mayor parte de la documentación archivística aparece registrado sólo como caballero de la Orden de Santiago ${ }^{8}$ y alférez mayor

3 Vid. Juan José Iglesias Rodríguez, Una ciudad mercantil en el siglo XVIII: El Puerto de Santa María, Brenes, Muñoz Moya y Montraveta, 1991.

4 Lidia AnEs, «Comercio con América y títulos de nobleza: Cádiz en el siglo XvIII», Cuadernos Dieciochistas, 2 (2001), págs. 136-137.

5 Este reconocimiento real resulta harto significativo por la celeridad con que se otorgó, apenas dos meses y medio después de la incorporación de El Puerto a la jurisdicción real, tras cuatrocientos años en manos del duque de Medinaceli. Para las relaciones entre la monarquía y la nobleza portuense, vid. Juan José Iglesias Rodríguez, Monarquía y nobleza señorial en Andalucía: estudios sobre el señorío de El Puerto (siglos XIII-XVIII), Sevilla, Universidad de Sevilla, 2003.

6 Fue el segundo oficio más caro, tras los 180.000 reales por los que se adjudicó la plaza de alguacil mayor a don Antonio Félix Reinoso Mendoza. Para estos datos, sigo el estudio de Jesús Manuel González Beltrán, «De señorío a realengo. Reflexiones sobre la incorporación de El Puerto de Santa María a la Corona (1729)», Revista de Historia de El Puerto, 32 (primer semestre, 2004), págs. 11-25. Asimismo, de gran interés son sus otras dos aportaciones al respecto, «Los regidores perpetuos de El Puerto de Santa María en el siglo XvIII. Rasgos socio-económicos», Revista de Historia de El Puerto, 9 (1992), págs. 51-85, y «Burguesía mercantil y gobierno municipal en la Bahía gaditana (II). Los comerciantes portuenses del siglo XVIII. Su proyección en la política local», en La burguesía española en la Edad Moderna, Valladolid, Universidad de Valladolid, 1996, tomo II, págs. 753-782.

7 Es decir, era un cargo vitalicio que además heredaban las siguientes generaciones de la familia.

8 Las pruebas para la concesión del título de caballero de la Orden de Santiago de Guillermo Tirry y Tirry se encuentran digitalizadas en el Portal de Archivos Españoles (Pares), Archivo Histórico Nacional (AHN), signatura OM-CABALLEROS_SANTIAGO, expediente 8062, fol. 1r.-135r. 
de El Puerto de Santa María, un oficio que heredó tras la muerte de su abuelo en 1745. Este nombramiento fue el comienzo de una dilatada carrera política durante la cual desempeñó diversos cargos públicos en el municipio portuense. De hecho, al año siguiente, cuando tan sólo contaba con veinte años, fue nombrado diputado de Fiestas y le encomendaron, junto al regidor Martín Reinoso, todos los preparativos tanto de las exequias por la defunción de Felipe V como de los fastos por la proclamación de Fernando VI. Su intervención constituyó una gran ayuda económica para el cabildo, puesto que Guillermo sufragó los gastos generados tanto por el retrato de Fernando VI, que mandó realizar y que posteriormente entregó al municipio, como del notable pendón real labrado para la ceremonia ${ }^{9}$. Probablemente este gesto aparentemente tan dadivoso le fue instado a Guillermo por su padre para acrecentar su poder como alférez mayor y ennoblecer el escudo de armas de su marquesado con las insignias de Castilla y El Puerto, hecho que se hizo efectivo en 1747 por decisión real ${ }^{10}$. Tras un lapso de diez años, reaparecerá de nuevo involucrado en el cabildo ejerciendo de síndico procurador mayor en 1756, año que marca un hito en su vinculación, cada vez más estrecha, a la política local de El Puerto. Quizá gracias a su carácter ecuánime fue comisionado en varias ocasiones para mediar en numerosos pleitos surgidos entre distintos organismos y el Ayuntamiento ${ }^{11}$.

A pesar de su intensa actividad en el cabildo portuense, circunscribir su vida a esta faceta sería menoscabar su personalidad. Detrás del ilustre político está el erudito ilustrado, el «caballero de exquisito gusto», como lo calificó An-

9 Hipólito Sancho de Sopranis, Historia del Puerto de Santa María desde su incorporación a los dominios cristianos en 1259 hasta el año mil ochocientos. Ensayo de una síntesis, Cádiz, Universidad de Cádiz, 2007, págs. 285-286.

10 Hipólito Sancho de Sopranis y Rafael Barris Muñoz, «El Pendón Real del Puerto de Santa María», en Rincones portuenses, Cádiz, Tipografía Ordóñez, 1926, págs. 151-177. Aunque la apreciación de Hipólito Sancho es muy acertada, no ha de entenderse como un hecho especialmente significativo en la familia Tirry ni tampoco aislado en el siglo XVIII, ya que fue una práctica habitual en las relaciones entre la nobleza y la monarquía ya desde finales de la centuria anterior. Muchos títulos nobiliarios fueron concedidos a comerciantes e industriales de las provincias de Sevilla y Cádiz gracias a la financiación prestada por éstos para las campañas militares de la dinastía borbónica. Además, hay que señalar cómo esta política era propiciada por la misma monarquía, ya que, junto a la solvencia económica, uno de los requisitos fundamentales para aspirar a un título real era precisamente la relación cualitativa de los servicios prestados a la corona. Es evidente que las gratificaciones reales siguieron otorgándose a la nobleza de título en virtud de una gran variedad de méritos alegados, como es el caso de Guillermo Tirry. Sobre este particular, vid. Lidia AnEs, «Comercio con América y títulos de nobleza...», op. cit., págs. 109-149.

11 Para una información más detallada de todos los cargos municipales que desempeñó a lo largo de su vida, vid. la semblanza del marqués de la Cañada que hacen José Ignacio BuHíGas CABrera y Enrique Pérez Fernández, «El marqués de la Cañada y su gabinete de antigüedades del siglo XvIII en El Puerto de Santa María», en José Beltrán Fortes, Fernando Gascó La Calle y José Tomás Saracho Villalobos (eds.), La Antigüedad como argumento. Historiografía de arqueología e historia antigua en Andalucía, Sevilla, Junta de Andalucía, 1994, págs. 205-221. 
tonio Ponz ${ }^{12}$. En este sentido, Guillermo fue un hombre de su época y, como tal, hubo de compaginar sus responsabilidades en el ámbito público con sus inquietudes intelectuales en la esfera de lo privado, asumiendo las primeras como una obligación adquirida tras la muerte de su abuelo y disfrutando con las segundas, alentadas desde su juventud por su padre. El estimulante entorno cultural que le rodeó propició sin duda el interés del III marqués de la Cañada por múltiples disciplinas, sintiendo una especial predilección por la arqueología. Esto se plasmó en un museo de antigüedades que albergaba su colección numismática y un gran número de esculturas de diverso origen. Junto a estas colecciones, el marqués dispuso su biblioteca en otro gabinete, adornado con una vasta colección de estampas, numerosos cuadros, entre los cuales destacan varios lienzos de Murillo ${ }^{13}$, y algunos objetos curiosos, como un microscopio y una cámara oscura.

Durante los últimos años de su vida debió de agravarse considerablemente la situación económica del marquesado. Para Buhígas Cabrera y Pérez Fernández, la boda de su hija María Dolores con el marqués de Ureña, Gaspar Molina de Zaldívar, en 1776, «representó para los Tirry superar una fuerte crisis económica» ${ }^{14}$. Otro indicio de ello es el hecho de que el marqués vendiese gran parte de su monetario a la Real Academia de la Historia ${ }^{15}$. Tras su muerte, su viuda, Francisca Lacy de Albeville, enajenó prácticamente todas sus colecciones ${ }^{16}$. La numerosa colección de estampas pasó por varios propietarios, hasta terminar en la de Sebastián Martínez, y su biblioteca fue vendida al noble jerezano Miguel María Panés González de Quijano, IV marqués de Villapanés.

12 Antonio Ponz, Viage de España, Madrid, Atlas, 1972, ed. facs., tomo XVII, carta sexta, pág. 271.

13 Vid. Alfredo Ureña UcEDA, «La pintura andaluza en el coleccionismo de los siglos XVI y XVII», Cuaderno de Arte e Iconografía, 13 (1998), t. VII, págs. 99-148, también disponible para su consulta en la siguiente dirección web: <http://fuesp.com/revistas/pag/cail36.html>.

14 J. I. Buhígas Cabrera y E. Pérez Fernández, «El marqués de la Cañada y su gabinete...», op. cit., pág. 215.

15 Llama la atención que Guillermo prefiriera vender su colección a la Academia antes que hacerlo en el extranjero, como se puede ver a través de los distintos ofrecimientos que les hizo. Sobre la correspondencia que mantuvieron tanto Guillermo Tirry como su padre con la institución para venderles el monetario, vid. Fátima Martín Escudero, Adela Cepas y Alberto Canto García, Archivo del Gabinete Numario: catálogo e índices, Madrid, Real Academia de la Historia, 2004.

16 Muchas de las fortunas nobiliarias del siglo XVIII decayeron a lo largo de la centuria debido a que el importe recaudado con las rentas fue insuficiente para los gastos generados por su posición social. Una de las causas más frecuentes fue la imposibilidad de afrontar los pagos que anualmente debían realizar a la corona para mantener el título nobiliario de Castilla. Sin embargo, los problemas económicos de Guillermo Tirry fueron de otra naturaleza, puesto que él estaba libre del pago anual de media annata y lanzas. Su abuelo, el fundador del marquesado, entregó los 160.000 reales fijados por el rey para la exención del impuesto, como recoge Lidia ANES, «Comercio con América y títulos de nobleza...», op. cit., pág. 136. 
A principios del siglo xx, Francisco Vindel fue el primer investigador contemporáneo que reparó en los libros del marqués, mencionándolo en un opúsculo sobre la bibliofilia en España ${ }^{17}$. Desde entonces, todos los estudios que han abordado algún aspecto sobre las otras colecciones del marqués de la Cañada han traído a colación su gran biblioteca. Entre sus coetáneos, los libros de Guillermo Tirry despertaron la curiosidad de insignes bibliófilos españoles. En efecto, Antonio Ponz elogió el carácter extraordinario de sus fondos en el Viage de España, pero también suscitó el interés del conde del Águila y del marqués de Villapanés. De hecho, la única referencia documental hasta ahora conocida que muestra una pequeña parte de dicha colección es la sucinta relación de libros que ha permanecido inédita en el legado bibliográfico del conde del Águila, localizado en el Archivo Municipal de Sevilla.

Entre los papeles que pertenecieron a don Miguel José Ignacio Espinosa Maldonado Saavedra y Tello de Guzmán, II conde del Águila, «máximo exponente de la afición al libro durante los reinados de los tres primeros Borbones» ${ }^{18}$, se encuentra el documento titulado la «Librería del Marqués de la Cañada. [Co] mpuesta de 3979 Volúmenes, se vendió al Mar[qu]és de Villapanés (de Xerez dela Frontera) en $[\ldots] \mathrm{P}^{\mathrm{s}}$.= Hai en ella los libros siguientes ${ }^{19}$. Se trata de uno de los cerca de cinco mil manuscritos que el conde del Águila tuvo entre sus fondos y que probablemente fue copiado del original por su secretario ${ }^{20}$. A pesar de que el legajo debió de ser muy voluminoso, dada la gran cantidad de libros que hubo de registrar, el documento conservado alcanza sólo treinta y seis títulos, ocupando apenas cuatro hojas en cuarto y, quizá lo más interesante, sin mostrar ningún signo que indique su término al final de la última entrada. Además, el epígrafe con el que se registra en el índice de la sección XI, «Apuntes sobre la librería del Marqués de la Cañada ${ }^{21}$, insinúa el carácter fragmentario del docu-

17 Francisco Vindel, Los bibliófilos y sus bibliotecas. Desde la introducción de la imprenta en España hasta nuestros días, conferencia dada en la Unión Ibero-Americana el día 26 de octubre de 1934, Madrid, Imprenta Góngora, 1934, pág. 29.

18 Francisco Aguilar Piñal, «El conde del Águila, insigne bibliófilo sevillano del siglo XVIII», en Temas sevillanos. Primera parte, Sevilla, Universidad de Sevilla, 2002, pág. 60.

19 Archivo Municipal de Sevilla (Ams), sección XI, $13\left(4 .^{\circ}\right) / 13$, fols. 58r.-59v.

20 El trazado de las grafías de este documento coincide con el que recoge el catálogo de los manuscritos de la biblioteca de don Miguel de Espinosa Maldonado Tello de Guzmán, conde del Águila, un listado manuscrito que seguramente realizó la misma persona, posiblemente el mismo secretario del conde del Águila, alrededor de 1786, y que puede consultarse en la Biblioteca General de la Universidad de Sevilla.

${ }^{21}$ AMs, Índice de la Sección Especial-Siglo XVIII, Sevilla, 1859, pág. 128 (el catálogo impreso no está numerado, por lo que la paginación que ofrecemos corresponde a la que aparece en el margen superior derecho escrita a mano). Esta manera de incidir en la naturaleza incompleta del listado llama la atención 
mento en 1859, cuando don José Velázquez y Sánchez inventarió los papeles del conde del Águila que el municipio hispalense adquiriera en 1809. Puesto que el documento carece de información puntual al respecto, sólo podemos ofrecer dos conjeturas, es decir, quizá debamos entender que el listado de los libros estuviese ya cercenado cuando el conde del Águila lo adquirió o bien que se dispersase tras la muerte del bibliófilo sevillano. Ambas posibilidades son plausibles, pero implican dos cronologías diferentes en relación al documento. El primer caso indica que el resto del listado debió de sustraerse poco después de 1779, tras morir el marqués de la Cañada, mientras que el segundo retrasa la fecha a 1784, año de fallecimiento del conde del Águila.

El inventario llama la atención especialmente por la profusa manera en la que se consignan los datos de cada obra (autor, título, año y lugar de publicación, e incluso formato), con pocos elementos erróneos y con una ortografía muy clara. Frente a tanta precisión en cuanto a los detalles bibliográficos de las obras, es significativo que no aparezca en ningún caso su tasación específica, sino el precio global de la venta. Aunque no podemos descartar que esta información se indicase al final del listado, una posibilidad un tanto extraña, lo más verosímil es que el precio de todo el conjunto estuviese reflejado al comienzo, como parece indicar la sigla correspondiente a pesos, $\left\langle\mathrm{P}^{\mathrm{s}} »\right.$, que aparece en el encabezamiento del documento. No hemos podido determinar la cifra exacta al quedar ésta solapada con el cosido el documento, ocultando parte de la información contenida en sus márgenes izquierdos. No obstante, esta carencia es subsanable, como veremos después. Por ahora, podemos establecer una relación entre la naturaleza o finalidad del documento y su contenido explícito. Hemos de recordar que normalmente los inventarios de libros son unos documentos muy limitados e insuficientes para conocer con seguridad los datos relativos a las obras que recogen, pero, en cambio, sí suelen ofrecer puntualmente y con regularidad el precio de venta de cada una de ellas. Sin embargo, como hemos señalado, en nuestro caso ocurre todo lo contrario. Por todo ello, creemos que puede deducirse que no estamos ante un documento notarial o, en su caso, no sería un inventario confeccionado para reflejar la venta sino realizado a modo de índice o catálogo de libros, ya fuera para su comprador, el marqués de Villapanés, o para los mismos herederos de don Guillermo Tirry.

Aunque el documento sobre la venta de la biblioteca del marqués de la Cañada esté incompleto, sabemos que con ella se saldó el censo de 5.000 pesos impuesto sobre la residencia familiar en 1762 a favor del III marqués de Villa-

significativamente, porque los documentos que recogen los fondos íntegros de otras librerías que interesaron al insigne conde aparecen presentados como «Catálogo de», en lugar de «Apuntes de», a lo largo de los 91 tomos de que consta esta sección. 
panés, el jerezano Miguel Andrés Panés y Pavón. Éste murió en 1776, por lo que fue Miguel María, su hijo, quien compró la biblioteca de los nobles portuenses. El precio de los volúmenes conseguidos ascendería grosso modo a unos 2.550 $\operatorname{pesos}^{22}$, una cantidad nada desdeñable para la época. Al igual que Guillermo Tirry, Miguel María fue un bibliófilo culto y refinado y, además, uno de los fundadores de la Real Sociedad Económica de Amigos del País de Jerez. Como director de dicho organismo, desempeñó una importante labor educativa con la creación de la primera biblioteca pública de Jerez, que estuvo ubicada durante algún tiempo en las dependencias de su propio palacio ${ }^{23}$. Los fondos de dicha biblioteca provenían de su colección privada, «aumentada notablemente con la que fue del Marqués de la Cañada», como señaló Antonio Ponz, quien, a continuación, aconsejaba «que dicho Señor Marqués ponga esta Oficina de la Literatura mas á mano de lo que está actualmente, para comodidad de los Literatos» ${ }^{24}$. Si bien con algunas limitaciones, la biblioteca de los Tirry estuvo a disposición de los estudiosos de la época en Jerez al menos hasta 1810, fecha en que las tropas francesas expoliaron parcialmente las posesiones del marqués y con ellas sus cerca de once mil volúmenes. Con todo, Miguel María volvería a formar otra estimable biblioteca añadiendo al fondo que le quedó sus nuevas adquisiciones, siendo el destino de ésta aún peor que el de la anterior. Tras la muerte del marqués en 1828, se hundió en la barra de Sanlúcar cuando por imposición testamentaria era trasladada a la ciudad de donde procedía el fundador del marquesado, Génova ${ }^{25}$.

\section{Una biblioteca aún mayor. Formación y disposición}

No podemos saber los libros del marqués de la Cañada que los franceses se llevaron de la biblioteca del marqués de Villapanés tras la ocupación de Jerez y,

22 Esta referencia es un cálculo estimativo que ofrecemos basándonos en la información aportada en el estudio de J. I. Buhígas Cabrera y E. Pérez Fernández, «El marqués de la Cañada y su gabinete...», op. cit., pág. 214, quienes, además, indican que el marqués de la Cañada estuvo pagando anualmente 150 pesos de rédito a los de Villapanés desde 1762.

23 Vid. Ramón Clavijo Provencio (coord.), Historia general del libro y la cultura en Jerez de la Frontera, Jerez, Ayuntamiento de Jerez, 2003, págs. 283-284; R. Clavijo Provencio, C. Puerto Castrillón y A. Gómez Martín, «El mundo del libro y las bibliotecas en el Jerez ilustrado», Revista de Historia de Jerez, 2 (1994), págs. 25-38; Juan Luis Sánchez Villanueva, «La Escuela de Enseñanza Primaria del Palacio de Villapanés», Revista de Historia de Jerez, 8 (2002), págs. 149-171. Sobre las sociedades económicas surgidas en Cádiz en el siglo XVIII, vid. Juan José IgLESIAS RoDRíGuez, Ilustración y sociedades económicas en la provincia de Cádiz, Salamanca, Universidad de Salamanca, 2006.

24 A. Ponz, Viage de España, tomo XVII, carta VI, pág. 271.

25 Vid. Ramón Clavijo Provencio, Jerez y los viajeros del siglo XIX. Ilustrados y románticos 1768-1868, Jerez, Biblioteca de Urbanismo y Cultura, 1989, págs. 46-47. 
en caso de no haberse interesado por todos, ignoramos igualmente cuántas obras del aristócrata portuense se perdieron en las costas gaditanas. En cualquier caso, los títulos registrados en el documento de la venta son lo único que ha quedado de aquel saqueo y del naufragio, pero esto no significa que constituya el final de toda la biblioteca del marqués de la Cañada ${ }^{26}$. Esta conjetura es lícita si tenemos en cuenta los datos confusos que sobre el número de volúmenes han aportado los distintos personajes que visitaron la casa en vida de Guillermo Tirry. Mientras Antonio Ponz estima que «era mucho lo que allí había [...], hasta siete mil volúmenes» ${ }^{27}$, el propio marqués de la Cañada en carta a Gregorio Mayans en 1750 especifica que tiene «una selecta biblioteca de cuatro mil cuerpos en todas lenguas y ciencias» ${ }^{28}$. Es probable que cuando escribiese su primera misiva a Mayans contase con esa cifra, pero ésta debió de aumentarse con nuevos ejemplares a lo largo de los veinte años que separan esa fecha de la visita de Ponz en el último cuarto de siglo. Otro testimonio que confirma nuestra hipótesis está recogido en La Ilustración Española y Americana. En un número de 1875 se inserta un artículo sobre varios ex libris curiosos y describe con suma precisión el que identificó los libros del marqués de la Cañada:

[...] compuesto de cuatro fajas: en la primera, o sea en jefe, medio león rampante, de gules, en campo de oro; en la segunda dos cruces recrucetadas de oro en azur; la tercera faja de plata, y en la cuarta, o sea en campaña, otra cruz recrucetada de oro sobre azur. Detrás del blasón la cruz de Santiago. Al timbre corona de Marqués (forma inglesa): celada de frente con seis rejillas, burulete y lambrequines, y por cimera medio león rampante, con escudete, en el cual se ve la cruz de Santiago de plata en gules. Soportes: dos leones con estandartes y en ellos sendos escudos, coronados por la real de España, representando el de la izquierda un castillo en gules y el de la derecha un león de plata. Por la parte inferior corre una cinta con la divisa E CRUCE LEO ${ }^{29}$.

26 Con certeza sólo podemos afirmar que el marqués de Villapanés compró un total de 3.979 volúmenes de la biblioteca del marqués de la Cañada, aunque desconozcamos igualmente la cantidad precisa de títulos que agrupaba dicha cifra. Dado que el término volumen es ciertamente ambiguo, hemos de precisar que en el listado se refiere al sentido lato del vocablo, «libro u obra escrita que constituye un solo cuerpo», según el Diccionario de uso del español de María Moliner, Madrid, Gredos, 2008 (ed. abrev.], pág. 523. De hecho, al recoger el único libro del inventario que contaba con más de un tomo indica el número de éstos, pero contabilizándolos como un único volumen en la misma entrada del listado: «Asturias ilustrada, por Trelles, 1736, folio, 2 tomos».

27 A. Ponz, Viage de España, tomo XVIII, carta II, pág. 60.

28 Antonio Mestre Sanchís, Correspondencia de los ilustrados andaluces, Sevilla, Junta de Andalucía, 1990, pág. 380 .

29 La Ilustración Española y Americana, XXXVII (8 de octubre de 1875), pág. 215. La referencia a esta revista, así como otros datos de interés sobre el ex libris del marqués de la Cañada, han sido tomados direc- 


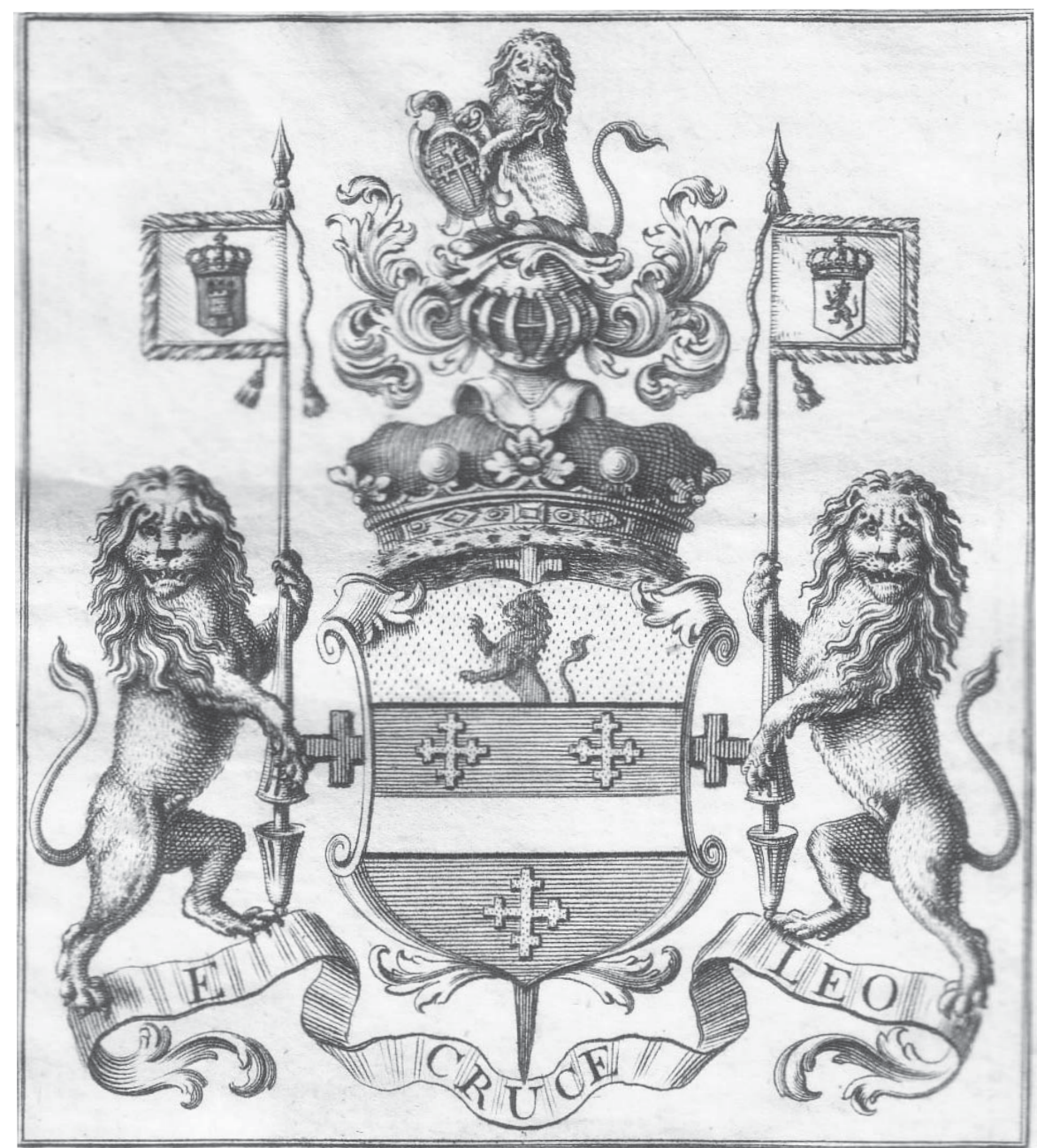

FIG. 1. Ex libris del marqués de la Cañada

El bello ex libris de Guillermo Tirry corresponde al escudo de armas del marquesado tras añadirle las insignias de Castilla y El Puerto sostenidas por dos leones, que le fueron concedidas por su actuación con motivo del ascenso al trono de Fernando VI, como mencionamos al tratar la biografía del marqués. A continuación, señala lo que más nos interesa: «[...] no es raro hallarlo, y con diversos tamaños por cierto, ó sea proporcionado al de los libros, en muchos volúmenes que hoy paran en diferentes bibliotecas de España», y que además «parece haber visto otra vez en algún libro de Gayangos». Estas referencias son pruebas fehacientes de que el marqués de Villapanés sólo consiguió una parte, aunque notable, de la biblioteca del marqués de la Cañada y dan a conocer

tamente de la información expuesta en uno de los posts del blog de Lamberto Palmart, a quien agradezco esta valiosa aportación y que puede consultarse en la siguiente dirección web: <http://mislibrosantiguos.blogspot. com/2008/04/historia-de-un-ex-libris.html>. 
la existencia de una gran cantidad de libros cuya dispersión probablemente se deba a su venta a otros bibliófilos españoles antes o después de fallecer en 1779; tampoco podemos descartar la posibilidad de que algunos bibliófilos adquiriesen los ejemplares robados por los franceses en Jerez. En cualquier caso, las distintas fuentes que hemos aportado establecen un cómputo total que oscilaría entre los cuatro mil y los siete mil libros.

Desde un punto de vista cuantitativo, la magnitud de la biblioteca del marqués de la Cañada va a la zaga de las dos grandes colecciones nobiliarias coetáneas, la de Campomanes y la del conde del Águila, pero supera el volumen de las compuestas por José de Gálvez, marqués de la Sonora, y también la colección de Sebastián Martínez ${ }^{30}$. Con frecuencia, el origen de las bibliotecas particulares más copiosas se halla en las herencias vinculadas a los mayorazgos, siendo el poder adquisitivo de un individuo directamente proporcional al caudal de su biblioteca ${ }^{31}$. En nuestro caso, es probable que parte del fondo de Guillermo Tirry pueda proceder del legado familiar, puesto que, como señala de nuevo Buigues, en las zonas portuarias los comerciantes acaudalados llegaron a reunir bibliotecas tan dignas como las de las élites aristocráticas ${ }^{32}$. Es posible que, gracias a la gran fortuna que amasó el primer marqués de la Cañada, éste pudiera adquirir la base de la biblioteca familiar. Dilucidar cuáles son las obras que cada uno aportó es una tarea harto difícil, aunque no imposible si tenemos en cuenta los datos biográficos que citamos en el primer capítulo.

La formación de una biblioteca tan nutrida y valiosa como la de los marqueses de la Cañada es una actividad que requiere una gran familiaridad con el mundo libresco y, sobre todo, disponer del tiempo y el espacio propicios para el estudio de los catálogos de libros o, en su defecto, estar en contacto con una serie de agentes que surtan tanto de las novedades como de las rarezas literarias y la adquisición de los ejemplares de otras personas en las almonedas públicas. Como vimos, el más anciano de los Tirry fue un hombre dedicado mayormente a la actividad comercial, sin que nos haya llegado un documento que lo relacione directamente con el mundo cultural. Sin embargo, Juan Tirry aunó el

30 La biblioteca de Campomanes contenía un total de 12.000 volúmenes y la de José de Galvez 2.300, según los datos aportados por Jean-Marc Buigues en «Los lectores: oficios, profesiones y estados», en Víctor Infantes, François LóPEZ y Jean-François Botrel (coords.), Historia de la edición y de la lectura en España, 1475-1914, Madrid, Fundación Germán Sánchez Ruipérez, 2003, pág. 429. La biblioteca del conde del Águila sobrepasaba entre manuscritos y títulos impresos un total de 12.500 aproximadamente, según Francisco Aguilar Piñal, «Una biblioteca dieciochesca: la sevillana del conde del Águila», Cuadernos Bibliográficos, 37 (1978), pág. 8. Finalmente, Sebastián Martínez atesoró en su biblioteca gaditana 2.442 tomos, como señala Antonio García-BAQUero González, Libro y cultura burguesa en Cádiz: la biblioteca de Sebastián Martínez, Cádiz, Fundación Municipal de Cultura, Cátedra Adolfo de Castro, 1988, pág. 39.

31 J.-M. Buigues, «Los lectores...», op. cit., pág. 430.

32 Ibidem, pág. 430. 
pragmatismo de su suegro y su pasión por la arqueología, comenzando el pequeño museo de antigüedades que después ampliaría su hijo. Llegó a comprar el monetario de Francisco Lelio Levanto, por lo que no sería extraño que su afán coleccionista alcanzase también a los libros y, en consecuencia, persiguiese primeras ediciones e incluso incunables, de los cuales hay algunas muestras en el parco listado con el que contamos. En cualquier caso, lo que sí hizo con certeza fue transmitirle a su hijo estas dos aficiones, como se desprende de la correspondencia de Guillermo Tirry con Mayans o Burriel. En base a ello, si bien podemos aceptar que la biblioteca del III marqués de la Cañada representa los gustos de tres poseedores, existe una notable diferencia en la consideración que tuvo para cada uno. Mientras que para el primer marqués el libro representaría sólo una mercancía de la que vanagloriarse en sociedad, su yerno y su nieto estimarían sus adquisiciones como un verdadero objeto de estudio. Además, es plausible inferir que Juan y Guillermo fueron los verdaderos bibliófilos que enriquecieron la biblioteca con una exquisita selección de ediciones, gracias a las cuales fue reconocida unánimemente por todos los que la consultaron como una gran colección de «libros raros y estimables» ${ }^{33}$.

El modo de consignar los asientos en el documento, sin un orden aparente y sin distinción alguna por autor, materia, fecha o lugar de publicación, es extraño y sumamente curioso. Los inventarios post mórtem, los catálogos, los índices y las tasaciones de libros pueden dar alguna información sobre su posible colocación en las bibliotecas, en cuyas estanterías suelen agruparse en función al orden cronológico de adquisición, por lotes temáticos, según las encuadernaciones y los distintos formatos de las obras o simplemente por el uso que se haga de ellas. Si bien es cierto que en la mayoría de los casos estos datos son un mero indicio de cómo pudo estar constituida la biblioteca, la relación indiscriminada de la «librería» del marqués de la Cañada es una señal de todo lo contrario. En las bibliotecas dieciochescas existe una especial correlación entre el espacio físico que ocupa el libro y la elección de éste, hecho que a su vez implica que dichas bibliotecas se conciban «como una representación de un universo mental determinado» ${ }^{34}$. El gran número de volúmenes y los formatos tan variados que recoge nuestro documento hacen necesaria una organización con buen criterio o, como asegura López-Vidriero, «con orden y con gusto, porque hacerlo de otra

33 A. Ponz, Viage de España, tomo XVIII, carta II, pág. 60. El agustino Enrique Flórez y el viajero inglés Richard Twiss hacen una valoración parecida a la de Ponz. Vid. Fray Francisco Méndez, Noticia de la vida y escritos del Rmo. P. Mtro. Fr. Enrique Flórez, Madrid, Imprenta de José Rodríguez, 1780, pág. 220; Richard Twiss, Travels through Portugal and Spain in 1772 and 1773, Londres, G. Robinson, T. Becket, J. Robson, 1775, pág. 220.

34 Ana Martínez Pereira, «Historia de la formación y evolución de las bibliotecas», en Víctor InfanTES, François LóPEZ y Jean-François Botrel (coords.), Historia de la edición..., op. cit., pág. 115. 
forma habría sido ridículo además de un pecado de lesa ilustración» ${ }^{35}$. Además, el hecho de que acomodara el tamaño del ex libris familiar a los diferentes formatos de sus obras delata una minuciosidad que sin duda también se reflejaría en la estructura del arrière-cabinet, cuya organización pudo basarse en la temática de las obras y la colocación de éstas depender de sus formatos. Explicar por qué aparece una distribución tan aleatoria en nuestro listado entraña una gran dificultad, ya que puede atender a múltiples razones, desde el registro por lotes o cajones en los que fueron trasladados hasta una enumeración que revele cómo estaban apilados o desordenados los libros en el momento de la venta.

\section{Análisis de los libros vendidos del marqués de la Cañada}

Desde un punto de vista cualitativo, la biblioteca debió de ofrecer un amplio abanico de materias. Dado que es imposible hacer un catálogo con todos sus contenidos, ofrecemos el estudio de las obras registradas en el inventario de la venta. El exiguo número de entradas del listado impide realizar un estudio exhaustivo de los libros de Guillermo Tirry que pasaron a las manos del marqués de Villapanés, por lo que el análisis de sus títulos resulta meramente orientador de lo que se vendió.

Centrándonos en este reducto bibliográfico, destaca en primer lugar un incunable poco conocido, la Cárcel de Amor de Diego de San Pedro, publicada junto con el epílogo de Nicolás Núñez $(T o l e d o, ~ 1500)^{36}$. Además de la novela sentimental del Cuatrocientos, sus gustos literarios abarcan desde los poetas latinos o la poesía épica culta hasta los libros de caballerías.

En cuanto a los clásicos latinos, nos encontramos con tres traducciones realizadas por poetas españoles del siglo XVII: la Eneida de Virgilio, el Robo de Proserpina de Claudio Claudiano y una antología de varios poetas latinos. En relación con la primera, se trata de la última traducción de la Eneida en el Seiscientos (Cádiz, 1698), compuesta por el portuense Juan Francisco de Enciso y Monzón. Mientras que esta obra no mereció ningún reconocimiento ${ }^{37}$, las

35 María Luisa LóPEZ-VIDrIERo, «El gabinete de un hombre de gusto. Manuales para la formación de bibliotecas en el siglo XVIII», en María Luisa LóPez-Vidriero y Pedro M. Cátedra (dirs.), El libro antiguo español IV. Coleccionismo y bibliotecas (siglos XV-XVIII), Salamanca, Universidad de Salamanca, 1998, pág. 460.

36 De hecho, esta edición sólo es citada por Antonio Palau y Dulcet en su Manual del librero hispanoamericano..., Barcelona, Librería Anticuaria de A. Palau, 1967, t. XIX, pág. 206, núm. 293.345. Las fichas catalográficas que hemos realizado de cada una de las entradas del listado pueden consultarse al final.

37 La valoración actual corrobora esta estimación. Vid. Alberto BlecuA, Signos viejos y nuevos: estudios de historia literaria, con un apéndice bibliográfico al cuidado de Xavier Tubau, Barcelona, Crítica, 2006, pág. 168. 
dos restantes constituyeron importantes versiones. Cuando apareció el Robo de Proserpina (Madrid, 1608) del granadino Francisco de Faría, tanto Cervantes como Lope de Vega elogiaron su poema ${ }^{38}$. Por su parte, la selección poética de José Morell, las Poesías selectas de varios Autores latinos, traducidos en verso castellano e ilustradas con notas de la Erudición (Tarragona, 1684), incluía la traducción más completa en su época de los epigramas de Marcial y de los poemas de Horacio.

El romancero erudito o historial se halla bien representado con los afamados Romances nuevamente sacados de historias antiguas de la crónica de España, compuestos por Lorenzo de Sepúlveda. Se trata de una de las dos reediciones de la obra que se hicieron en 1566, en concreto la preparada por la imprenta de Felipe $\mathrm{Nucio}^{39}$, quien a su vez reorganizó y aumentó la nutrida colección de Sepúlveda — de casi cincuenta romances eruditos basados en crónicas- con otros textos inéditos «nunca vistos compuestos por vn cauallero Cesario, cuyo nombre se guarda para mayores cosas», como añade el mismo Nucio al título de la obra. Otra obra representativa de la épica es la epopeya en doce cantos titulada Primera parte de Cortés Valeroso, y Mexicana (Madrid, 1588), de Gabriel Lasso de la Vega. El mismo autor aumentaría este panegírico dedicado a Hernán Cortés con otros trece cantos más en 1594, una reedición que no se menciona en nuestro inventario.

Este tipo de obras de carácter encomiástico debieron de interesarle al marqués especialmente por las noticias históricas e informaciones variadas que ofrecía su lectura. De hecho, pertenecientes a este género destacan otros dos títulos: la Epaenesis Iberica (Amberes, 1632) y el Memorial de cosas notables (Guadalajara, 1564). La primera es un poema en hexámetros compuesto por el humanista conquense Luis Tribaldos de Toledo en el que elogia todos los territorios hispánicos de la época. Esta esmerada edición de Baltasar Moretus

38 Cervantes lo hizo en el capítulo II segundo de su Viaje al Parnaso (Madrid, 1614) y Lope de Vega lo recoge en el canto XIX de la Jerusalén Conquistada (Madrid, 1609). Faría tradujo la obra basándose en el Cl. Claudiani Proserpinae Raptus cum Iani Parrhasii Commentariis (París, 1511). La versión castellana no se reeditará hasta prácticamente dos siglos después, en 1806, a cargo de las imprentas madrileñas de Sancha y Repullés, y, en consecuencia, sería una de las obras más deseadas para todo ilustrado que quisiera estudiar la recepción en España del poema de Claudiano o cotejar éste con las traducciones de nuestros poetas. Además, esta traducción es la única conservada de otras dos que compusieron Fernando de Herrera y Lope de Vega, como ha señalado José María Micó, «Verso y traducción en el Siglo de Oro», Quaderns. Revista de Traducció, 7 (2002), págs. 83-94. En la actualidad, contamos con la edición electrónica que nos ofrece Jesús M. Morata, para quien la versión de Faría es una Proserpina a lo divino. Véase también María Dolores Castro Jiménez, «De raptu Proserpinae de Claudiano en la traducción de Francisco de Faría», en Actas del VII Congreso Español de Estudios Clásicos, v. III, Madrid, Universidad Complutense, 1989, págs. 433-440.

39 La otra reedición fue llevada a cabo por Pedro Bellero. Para más datos, vid. Paloma Díaz Mas, «El Romancero, entre la tradición oral y la imprenta popular», Destiempos, 15 (2008), págs. 115-129. 
iba acompañada de un mapa al inicio de la obra ${ }^{40}$. Por otro lado, gracias al Memorial que sobre su propia familia redactó Íñigo López de Mendoza y Pimentel, pudo el marqués de la Cañada conocer la genealogía y posesiones del ducado del Infantado.

Por lo que respecta a la tradición caballeresca, contó el marqués con dos ejemplares de gran valor y rareza: el Reynaldos de Montaluán (Alcalá, 1563) y el Amadís de Gaula (Salamanca, 1575). En relación con el primero, la edición referida se corresponde con la primera y segunda parte de la obra que preparó Sebastián Martínez, una obra de la que se conservan pocos ejemplares ${ }^{41}$. En cuanto al Amadís, se trata de la edición que, basándose en el texto fijado en Burgos en 1563, preparó Lucas de Junta en la imprenta de Pedro Lasso, una joya literaria cuyos ejemplares se encuentran dispersos por varias bibliotecas tanto nacionales como extranjeras ${ }^{42}$. El gusto por las hazañas heroicas no se limita a estas dos obras, como confirma el hecho de que encontremos en el inventario la continuación del Amadís, El ramo que de los quatro libros de Amadís de Gaula sale, llamado las Sergas del muy esforzado Cavallero Esplandián, hijo del excelente Rey Amadís de Gaula, de Garci Rodríguez de Montalvo en su última edición (Alcalá de Henares, 1588), y El libro del famoso y muy esforzado caballero Palmerín de Olivia, en su segunda impresión toledana (1580), hecha por Pedro López de Haro, dos obras que también formaron parte de la gran biblioteca de don Diego Sarmiento de Acuña, primer conde de Gondomar ${ }^{43}$. Por último, otra

40 Para más información sobre esta obra y la geografía que alaba, vid. Trinidad Arcos PEREIRA y Gregorio Rodríguez Herrera, «Las islas del Atlántico en la Epaenesis Iberica de Luis Tribaldos de Toledo», Humanistica Lovaniensia, 51 (2002), págs. 273-284.

41 Vid. Julián Martín Abad, La imprenta en Alcalá de Henares (1502-1600), Madrid, Arco/Libros, 1991, pág. 715. La III parte, conocida como la Trapesonda, fue editada también en Alcalá de Henares y en esa misma fecha pero por Andrés de Angulo, como recogen José Manuel Lucía Megías y Carlos Alvar Ezquerra, «Los libros de caballerías en la época de Felipe II», en Isabel Lozano-Renieblas y Juan Carlos Mercado (coords.), Silva: studia philologica in honorem Isaías Lerner, Madrid, Castalia, 2001, págs. 29-36. Sabemos que la Biblioteca Universitaria de Valencia tiene esta misma obra, pero en la edición que se hizo al año siguiente en Burgos. La Biblioteca Nacional de Madrid sólo cuenta con la Trapesonda, en una edición muy tardía, la de 1585 hecha en Perpiñán.

42 La edición burgalesa de 1563 también sirvió de base a otra edición realizada en Salamanca en 1575, a costa de Vincenzo de Portonariis. Vid. Mercedes Fernández Valladares, La imprenta en Burgos (1501-1600), Madrid, Arco/Libros, 2005, pág. 1.014. Para consultar la localización de los ejemplares conservados, vid. José Manuel Lucía Megías, «Libros de caballerías castellanos en la Biblioteca del Cigarral del Carmen (Toledo)», Tirant. Butlletí Informatiu i Bibliogràfic, 8 (2005), consultado en su versión PDF en Internet en la dirección <http://parnaseo.uv.es/Tirant/Butlleti.8/LibrosCaballeria.pdf>.

43 La biblioteca del conde de Gondomar contaba con una colección de dieciséis libros de caballerías. Para ver el listado completo, vid. José Manuel Lucía Megías, «Llibres de cavalleries a la biblioteca d'Alonso Quijano», en el catálogo de la exposición Del Tirant al Quixot: la imatge del cavaller, Valencia, Universidad de Valencia, 2005, pág. 66. Un ejemplar de las Sergas de Esplandián también se encuentra en la Biblioteca del Cigarral del Carmen, vid. José Manuel Lucía Megías, «Libros de caballerías castellanos...», donde puede igualmente consultarse la ubicación de más ejemplares localizados en otras bibliotecas. 
representación de la cultura caballeresca medieval la encontramos en la Crónica llamada el triunpho de los nueve preciados de la Fama, una traducción del Triomphe des Neuf Preux realizada por Antonio Rodríguez Portugal en 1530. Dos años después, Juan Navarro se encargó de reeditarla en Valencia, uno de cuyos ejemplares es el que tuvo el marqués de la Cañada, aunque conocemos que también estuvo entre los anaqueles de la VI condesa de Lemos ${ }^{44}$. El tema de los Nueve de la Fama proporcionaría muchos datos curiosos sobre heráldica, una materia gustosa para el marqués.

Basándonos en nuestro breve catálogo, podemos pensar que la religión no ocupó un lugar importante entre sus lecturas, puesto que sólo aparece una hagiografía: la Vida de san Hermenegildo, rey y mártir de España, grano fecundo, que con su muerte aumentó en estos reynos la mejor cosecha (Madrid, 1680), escrita por el presbítero madrileño Manuel López Ponce de Salas. No obstante, esta obra relaciona la historia de la monarquía hispánica con la biografía del santo, trascendiendo con ello el alcance del resto de las hagiografías al uso ${ }^{45}$.

En relación con las obras de pensamiento político, resultan muy interesantes tres tratados que, a modo de espejo de príncipes, describen los valores sobre los que ha de cimentarse una monarquía ideal. Se trata en cualquier caso de obras que tratan de los siglos XVI y XVII, por lo que no nos sirven para conocer el grado de implicación del marqués en las cuestiones relativas al poder de su época ${ }^{46}$. Estos tratados son el Verdadero gobierno de esta Monarquía, tomando por su propio sujeto la conservación de la paz (Valencia, 1581), de Tomás Cerdán de Tallada, la Soberanía del reino de España (Córdoba, 1626), de Alfonso Carrillo Laso de la Vega, y, finalmente, el Séneca juez de sí mismo, impugnado, defendido y ilustrado. En la causa política, y moral que litigan Don Alonso Núñez de Castro, Don Diego Ramírez de Albeada y Don Juan Baños de Velasco y Acevedo (Burgos, 1684), escrito por Francisco de Zárraga. Las tres obras tienen un nexo en común: abogar por una soberanía consolidada en los principios cristianos y en un riguroso sentido de la justicia ${ }^{47}$.

44 Para más detalles, vid. María Isabel Barbeito Carneiro, «La biblioteca de la VI condesa de Lemos», en Varia bibliographica: homenaje a José Simón Díaz, Kassel, 1988, págs. 67-85.

45 La obra de Ponce de Salas remonta a San Hermenegildo, el primogénito del rey visigodo Leovigildo, la genealogía de los reyes españoles, en un intento de ensalzar conjuntamente tanto la figura del mártir visigodo como de Carlos II, como ha estudiado Inmaculada Rodríguez, «Los reyes santos», en Víctor Mínguez (ed.), Visiones de la monarquía hispánica, Castellón, Universitat Jaume I, 2007, págs. 133-170.

46 Nos referimos a las polémicas suscitadas en torno a las prerrogativas reales defendidas por los novatores e ilustrados regalistas frente a la intromisión de la iglesia en el ámbito civil.

47 Mientras que los dos primeros tratados se centran exclusivamente en ilustrar al monarca sobre la manera de hacer efectivos esos objetivos, la obra de Francisco de Zárraga amplía esa ejemplaridad al resto de los hombres, usando las máximas de Séneca para refutar las obras que sobre el mismo tema escribieron Alonso Núñez de Castro, Baños de Velasco y Diego Ramírez de Albelda. 
La historia es, sin duda, la materia de la que hay más volúmenes en el listado de libros del marqués de la Cañada. Hay que mencionar que todas estas obras se circunscriben únicamente a la historia de España. Entre ellas sobresalen especialmente cinco estudios historiográficos centrados en el origen de las provincias catalanas, como el Resumen historial de las grandezas y antigüiedades de Gerona (Barcelona, 1678), de Juan Gaspar Roig y Jalpí, la Crisi de Cataluña hecha por las naciones estrangeras (Barcelona, 1685), de Manuel Marcillo, la conocida como Tortosa, ciudad fidelísima y ejemplar (Madrid, 1641), de Vicente Miravall y Florcadell, o la obra de Jerónimo Pujades, Corónica universal del Principat de Catalunya... (Barcelona, 1609), un título que también encontramos en la biblioteca de Mayans ${ }^{48}$. También se interesó el marqués por conocer el pasado de otros puntos de la geografía española: Calatayud, Carmona y Asturias; de esta última se registran dos tratados diferentes.

Dentro de este ámbito se sitúan otras dos obras: por un lado, el Retrato político del señor rey de Castilla don Alfonso el octavo (Valencia, 1679), la biografía histórico-política que hizo Gaspar de Mercader y Cervellón, y, por otro, la Fundación, nombres y armas de Astorga (Madrid, 1639), del presbítero Pedro Junco, un tratado en el que los conocimientos históricos se imbrican con los filológicos para dilucidar la etimología de dicha localidad.

Otro apartado interesante lo componen las genealogías, que están representadas en el inventario por tres títulos. En primer lugar, destaca la obra de Tomás de Llano el Noviliario de casas y linajes de España (Valladolid, 1653), en el que se describen las redes de parentesco de la aristocracia hispánica. De un alcance mucho más limitado son los dos libros restantes. Así, en segundo lugar, nos encontramos con una de las obras de Juan de Orche, su particular hagiografía sobre la vida del patrón de Segovia, Historia de la vida del glorioso $S$. Fructos patrón de la ciudad de Segovia, y de sus hermanos San Valentín y Santa Engracia... (Valladolid, 1610), en la que traza su biografía mientras realiza el compendio de los reyes cristianos desde los albores de la Edad Media. Por último, citaremos la primera parte del tratado de Juan Francisco de Montemayor de Cuenca sobre la nobleza aragonesa.

Completan la relación otros títulos de materias muy dispares entre sí y que, en consecuencia, no podemos encajar en ninguna de las clasificaciones temáticas que acabamos de tratar. Como mencionamos al principio, una de las grandes aficiones del marqués fue el coleccionismo de antigüedades, que, a su vez, tuvo su correlato en la biblioteca a través de dos títulos, uno sobre numis-

48 Vid. Antonio Mestre SAnchís, «La formación de la biblioteca de un erudito de la ilustración: Mayans y Siscar», en Pedro M. Cátedra y María Luisa López-Vidriero (dirs.), El libro antiguo español VI. De libros, librerías, imprentas y lectores, Salamanca, Universidad de Salamanca, 2002, págs. 219-240. 
mática y otro sobre epigrafía. En relación a este último, se trata de la Inscripción del sepulcro de Saturnino Penitente, descubierta en el año 1650 ([s. 1.], 1650), que ilustrara en esa misma fecha el poeta José García de Salcedo Coronel ${ }^{49}$. En cuanto a la numismática, la adquisición de la Verdadera declaración de las monedas antiguas que se han hallado en un edificio antiguo que se ha descubierto debajo de tierra en el Alcazaba de Granada, por febrero de este año de 1624 (Madrid, 1624), obra de Miguel Vergara Gaviria, debió de serle de gran utilidad al marqués para clasificar mejor las piezas de su propio monetario. A estas dos referencias debemos añadir el tratado de equitación titulado Libro nuevo bueltas de escaramuza, de gala, a la gineta (Puerto de Santa María, [s. a.]), que contenía más de cincuenta grabados ilustrativos de este arte ecuestre heredado de los bereberes.

Por último, hemos reservado para el final del análisis dos entradas que clasificaremos como «raras». Una de ellas es el poema de Juan Soares de Alarcón titulado La Infanta coronada, por el Rey Don Pedro, Doña Inés de Castro: en octava rima (Lisboa, 1606), al que le debemos la introducción del tema de Inés de Castro en la literatura peninsular. La obra fue editada por Pedro Crasbeeck en dos formatos diferentes (en cuarto y en octavo), pero no contó con una reedición posterior. Se han conservado muy pocos ejemplares de ambas ediciones principes en las bibliotecas españolas ${ }^{50}$. El otro es, a nuestro juicio, el documento más notable de todos, y está recogido en el inventario de la siguiente manera: «Executoria y Privilegios de Medina Sidonia, 1602 en $4^{\circ} »$. A pesar del formato, no se trata de un impreso, sino de un manuscrito, del cual sólo se ha conservado

49 El descubrimiento tuvo una gran repercusión puesto que, además de Salcedo Coronel, también despertó el interés de Juan Tamayo de Salazar y Juan Gómez Bravo, como informa Mayans a Francisco Forner en la carta del 10 de julio de 1758, que puede consultarse en la Biblioteca Valenciana Digital en la siguiente dirección: <http://bv2.gva.es/es/corpus/unidad.cmd?idUnidad=47997\&idCorpus=20000\&posi cion=1>. En dicha carta agradece a Forner la remisión de la obra de Salcedo Coronel. Otra muestra del interés que tuvo entre los ilustrados el sepulcro de Saturnino es el hecho de que Diego Fernández de Linares le adjuntase una copia de la inscripción a Jovellanos en una carta fechada el 01-05-1792, que se encuentra entre los documentos de la Real Academia de la Historia. Esta carta está recogida con la signatura CAIO/9/3932/3(1) en la obra que preparó Rosario Cebrián Fernández, Comisión de Antigüiedades de la Real Academia de la Historia: antigüedades e inscripciones 1748-1845. Catálogo e índices, Madrid, Real Academia de la Historia, 2002, pág. 109.

$50 \quad$ El marqués de la Cañada tuvo el volumen en cuarto, del que en nuestro país sólo contamos con el ejemplar localizado en la Biblioteca Pública de Castilla-La Mancha de Toledo, según los datos que aparecen en el Catálogo Colectivo del Patrimonio Bibliográfico Español. El volumen en octavo se encuentra en la Biblioteca de la Universidad de Oviedo. En cambio, Portugal cuenta con cinco ediciones del volumen en cuarto (una en la Biblioteca de la Universidad de Coímbra y cuatro en la Biblioteca Nacional), aunque no haya conservado ningún ejemplar en octavo, según la información de su Base Nacional de Datos Bibliográficos (Porbase). Conocemos que perteneció a las bibliotecas de Eugenio Asensio y a la del bibliófilo portugués Manuel de Almeida gracias a la aportación de Adrien Roıg, «La infanta coronada de Juan Soares de Alarcón (1606)», en Actas del VII Congreso de la Asociación Internacional de Hispanistas, Roma, 1981, vol. II, págs. 893-901. 
la copia de una parte de su contenido: los privilegios. Esta valiosa copia se encontraba dentro de los «Apuntes Inéditos del S(eñ)or D(o)n Antonio Delgado», que fueron donados a la Real Academia de la Historia por Juan R. Cayón el 13 de diciembre de 1999. Para calibrar mejor la importancia del manuscrito que atesoró el marqués de la Cañada y valorar el alcance de lo que nos ha llegado de éste, es pertinente transcribir la información recogida por la Academia ${ }^{51}$ :

Anónimo. Privilegios de la Ciu(da)d de Medina Sidonia según se hallan en un Códice q(u)e posee el Marqués de la Cañada V(eci)no de el Puerto de S(an)ta María, en el q(u)e se contiene una executoria librada por la R(ea)l Chanz(illerí)a de Granada a favor de dicha Ciu(da)d en pleito q(u)e tubo con el Duque de su titulo, el de Medinaceli, y los Concejos de la V(ill)a de Ximena, Puerto de S(an)ta María y el Duque de Alcalá, Marq(ue)s de Tarifa, y las ciudades de Xerez de la Frontera, Cádiz, Ronda, Arcos, Sanlucar de Barrameda, Chiclana, Bejer, Conil, Tarifa, Casares, y los Molares, Lazerna, Carmona, Puerto R(ea)l, Bornos, Utrera y Lebrija: cuya executoria se libró en 25 de Junio de 1565 años; y en ella están insertos los citados Privileg(io)s de dicha Ciu(da)d de Medina Sidonia; sacados de los Privilegios Originales del Archibo de la misma ciudad en virtud de Provisión R(ea)l de S(u) Mag(esta)d p(o)r Diego Venegas es(criba)no y Receptor en dicha Chanz(illeri)a de Granada, de todo lo qual se mandó dar un traslado a la citada ciudad de Medina, y con efecto se sacó en molde todo a la letra p(o)r Juan Sánchez de Herrera es(cri) bano $p(u b l i)$ co en 9 de Oct(ub)re de 1602 años como todo consta y se manifiesta p(o) $r$ las firmas originales $q(u)$ e están en dicho Códice, q(u)e no tiene año, ni Lugar de impresión.

1602. Copia del original del siglo XIX.

Ms.- un cuad. en $4^{\circ}$.-55 p.-fol. 170-198.- $21 \times 15,5$ cm.- cosido.-en primera página margen derecho se lee de la misma letra: se vendio su librería al Marq(ue)s de Villa Panes, vecino de Xerez de la Frontera.

El marqués de la Cañada poseyó el códice que Juan Sánchez de Herrera copió en 1602 de la ejecutoria original (25 de junio de 1565). En dicha ejecutoria, además de los datos pertinentes sobre el pleito entre el duque de Medinaceli y los vecinos de Medina Sidonia, aparecían los privilegios de ésta. A su vez, estos privilegios se copiaron directamente del códice que tuvo el marqués de la Cañada, seguramente aún en vida de éste y por alguno de sus amigos ${ }^{52}$, eruditos

51 Juan Manuel Abascal Palazón, Rosario Cebrián Fernández, Manuscritos sobre antigüiedades de la Real Academia de la Historia, Madrid, Real Academia de la Historia, 2006, págs. 82-83, referencia 9-8073-6.

52 La entrada que acabamos de transcribir es sumamente prolija en datos, por ello es muy significativo el hecho de que al comienzo se afirme que «es un códice q(u)e posee», en lugar de especificar «que poseyó» 
o académicos, que visitaron su casa en busca de información sobre documentos jurídicos antiguos y difíciles de consultar o conseguir ya en el siglo XVIII. De esta copia salió al menos una más en el siglo XIX, que es justamente el original del que proviene la que se encuentra en la Academia de la Historia. Como vemos, el códice del marqués desapareció, quizá en la Barra de Sanlúcar, dejando sólo esta parcial estela anónima.

Como vemos, «estos pocos, pero doctos libros juntos» revelan que el bagaje cultural de que disponía su propietario era amplio. En efecto, la biblioteca se caracteriza por una gran heterogeneidad de materias: la presencia de los clásicos grecolatinos, la historiografía, los nobiliarios, la numismática, los tratados científicos, los libros de caballerías, etcétera. Estas preferencias están íntimamente vinculadas a la vida intelectual del marqués, su dimensión más interesante y humana, y no tanto a los fondos esperables en la biblioteca de un alférez, es decir, guarda mayor afinidad con los gustos de un aristócrata que con los de un oficial de un cabildo municipal o con los de una persona dedicada, como también era su caso, al comercio. Con toda la provisionalidad que tienen los datos con los que contamos, las lecturas de Guillermo Tirry no constituyeron una mera herramienta de trabajo para el marqués, sino todo lo contrario. En este sentido, hay que relacionar su figura con la de los gaditanos Pedro Alonso de O'Crowley, Sebastián Martínez, el conde de Maule y Nicolás Böhl de Faber ${ }^{53}$.

Como fue habitual entre los ilustrados, Guillermo Tirry también se decantó especialmente por los poetas del mundo clásico. En el inventario aparece un título original en latín y, sin embargo, hay tres traducciones de poesías latinas. En nuestra opinión, el marqués tuvo conocimientos de latín y probablemente leería a dichos poetas en esta lengua, aunque seguramente quiso contar con sus respectivas traducciones al castellano para cotejar las distintas versiones de los textos. La presencia de obras originales en francés y en catalán completa el repertorio de lenguas que pudo dominar o conocer, el cual no deja de ser el panorama lingüístico propio de todos los eruditos dieciochescos.

el marqués de la Cañada. Por lo que podemos suponer que así ha ido transmitiéndose la información a lo largo de los siglos en las distintas copias que se hicieron con posterioridad. La persona que hizo la copia debió de conocer al marqués de la Cañada e interesarle tanto su «librería» como para llegar a añadir con posterioridad el paradero de ésta: «se vendio su librería al Marq(ué)s de Villa Panes, vecino de Xerez de la Frontera». No obstante, lo que no deja lugar a dudas es que fue la misma persona la que copió el códice del marqués y anotó la venta de su biblioteca, pues la caligrafía de ambos escritos es idéntica.

53 A este respecto, hay que recordar que frente a las grandes bibliotecas nobiliarias de la época, caracterizadas por una gran variedad de títulos, el resto de la población contaba con un número reducido de obras relacionadas directamente con su categoría socioprofesional, como fueron las del jurista Vicente Pulciani, el almirante Antonio de Ulloa, el médico Francisco Canivell o el arquitecto Torcuato Cayón. Vid. Manuel Ravina, «El mundo del libro en el Cádiz...», op. cit., págs. 93-94. 
El inventario contiene obras comprendidas entre finales del siglo XV y mediados del siglo XVIII. Si bien es cierto que predominan las obras de los siglos áureos, no podemos saber el alcance de este dato por el exiguo número de obras que representa respecto al resto de la biblioteca perdida.

Un dato particularmente interesante es que la gran mayoría de los libros reseñados en el inventario son ediciones principes. Si a ello unimos el acopio de títulos en diversos formatos ${ }^{54}$, obtenemos el perfil de un hombre con una verdadera vocación bibliófila. Así pues, podemos pensar que el tercer marqués de la Cañada heredó y amplió la «biblioteca patrimonial» de sus predecesores hasta convertirla en una gran «biblioteca museo $»^{55}$, conocida y admirada por muchas de las grandes personalidades de la Ilustración española. Por todo ello, el inconcluso inventario de sus libros constituye un pequeño resquicio abierto a la cultura libresca portuense y gaditana, y a la cultura ilustrada española en un sentido más lato.

\section{Inventario y fichas catalográficas}

Como complemento al análisis de las lecturas del marqués, nos parece conveniente aportar las fichas catalográficas de los libros que aparecen reflejados en el documento de la venta de su biblioteca. Ello además permitirá estimar con más rigor el valor de los volúmenes que adquirió el marqués de Villapanés y conocer con mayor certeza las ediciones que tuvo el marqués de la Cañada. Para ello, en primer lugar, hemos numerado las entradas del listado y se han transcrito los datos de los libros de la misma manera que aparecen en el manuscrito que hemos presentado, si bien resaltándolos en cursiva.

A continuación, se han examinado todos los libros atendiendo a los siguientes criterios: nombre de autor; título de la obra; lugar y año de impresión; formato, sólo en el caso de que éste no coincida con el recogido en los distintos repertorios bibliográficos; signatura topográfica de la fuente bibliográfica de la cual extraemos todos los datos anteriores.

Al final, se especifica en las notas cualquier tipo de irregularidad que pre-

54 En los estudios bibliográficos modernos ocupa un lugar destacado el soporte que presentan los libros, es decir, «la relación entre forma y sentido» que señaló Roger CHARTIER, «Lecturas y lectores populares desde el Renacimiento a la época clásica», en Guglielmo Cavallo, Roger Chartier y Robert Bonfil (coords.), Historia de la lectura en el mundo occidental, Madrid, Taurus, 2004, pág. 424. Conscientes de ello, al identificar cada una de las obras que aparecen en el inventario, haremos las valoraciones pertinentes sobre los formatos en las fichas bibliográficas.

55 Tomamos está nomenclatura de los estudios citados de Víctor Infantes, Del libro áureo, Madrid, Calambur, 2006, pág. 168, y A. Martínez Pereira, «Historia de la formación...», op. cit., págs. 116-117. 
senten las entradas del listado de libros del marqués de la Cañada respecto a las fuentes consultadas. Asimismo, también aportamos la identificación de cada obra en varios repertorios bibliográficos. En general, las obras se han presentado con la información procedente del Catálogo Colectivo del Patrimonio Bibliográfico Español (CСPB), salvo en los casos en que ha sido necesario recurrir a otras fuentes. No obstante, en cada una de las fichas catalográficas se indica la procedencia de todos sus datos ${ }^{56}$. El nombre del autor, los títulos de las obras y su lugar de impresión se registran en nuestras fichas con las grafías de la fuente de la que proceden.

Las entradas conservadas del listado de libros vendidos de Guillermo Tirry son las siguientes:

56 Las abreviaturas de los repertorios bibliográficos consultados son las siguientes: Aguilar Piñal: Francisco Aguilar Piñal, Bibliografía de autores españoles del siglo XVIII, Madrid, Consejo Superior de Investigaciones Científicas, 1981-2002, 10 volúmenes; Aguiló y Fuster: Mariano Aguiló y Fuster, Catálogo de obras en lengua catalana impresas desde 1474 hasta 1860, Madrid, Establecimiento Tipográfico Sucesores de Rivadeneyra, 1927; Alcocer: Mariano AlCocer y MARTínEz, Catálogo razonado de obras impresas en Valladolid: 1481-1800, Valladolid, Casa Social Católica, 1926; Catalina García: Juan Catalina García, Biblioteca de escritores de la provincia de Guadalajara y bibliografía de la misma hasta el siglo XIX, Madrid, Establecimiento Tipográfico Sucesores de Rivadeneyra, 1899; Escudero: Francisco Escudero y Perosso, Tipografía Hispalense. Anales tipográficos de la ciudad de Sevilla desde el establecimiento de la imprenta hasta fines del siglo XVIII, Madrid, Establecimiento Tipográfico Sucesores de Rivadeneyra, 1894; Fernández Valladares: Mercedes Fernández Valladares, La imprenta en Burgos (1501-1600), Madrid, Arco/Libros, 2005, 2 volúmenes; Gallardo: Bartolomé José Gallardo, Ensayo de una biblioteca española de libros raros y curiosos, Madrid, Imprenta y Estereotipia de M. Rivadeneyra, 1863-1889, 4 volúmenes; Gayangos: Pascual de GaYangos, $\mathrm{Li}^{-}$ bros de caballerías, Madrid, Imprenta y Estereotipia de M. Rivadeneyra, 1857; López-Huertas: María José LóPez-Huertas Pérez, Bibliografía de impresos granadinos de los siglos XVII y XVIII, Granada, Universidad de Granada, Servicio de Publicaciones, 1997, 3 volúmenes; Lucía Megías: José Manuel Lucía Megías, Imprenta y libro de caballerías, Madrid, Ollero y Ramos, 2000; Marsá: María Marsá, Materiales para una historia de la imprenta en Valladolid (siglos XVI y XVII), León, Universidad de León, 2007; Martín Abad: Julián MARTíN AваD, La imprenta en Alcalá de Henares (1502-1600), introducción a la «Tipobibliografía Española» de José Simón Díaz, Madrid, Arco/Libros, 1991, 3 volúmenes; Moreno Garbayo: Justa Moreno Garbayo, La imprenta en Madrid (1626-1650) (materiales para su estudio e inventario), edición, introducción e índices de Fermín de los Reyes Gómez, Madrid, Arco/Libros, 1999, 2 volúmenes; Palau: Antonio Palau y Dulcet, Manual del librero hispanoamericano: bibliografía general española e hispanoamericana desde la invención de la imprenta hasta nuestros tiempos con el valor comercial de los..., Barcelona, Librería Anticuaria de A. Palau, 1948-1967, 36 volúmenes; Peeters-Fontainas: Jean Peeters-Fontainas, Bibliographie des impressions espagnoles des PaysBas méridionaux, Niewkoop, B. de Graaf, 1965, 2 volúmenes; Pérez Pastor, Bibliogr. Madrileña: Cristóbal Pérez Pastor, Bibliografía Madrileña o descripción de las obras impresas en Madrid, Madrid, Tipografía de los Huérfanos, 1891-1907, 3 volúmenes; Pérez Pastor, Toledo: Cristóbal Pérez Pastor, La imprenta en Toledo: descripción bibliográfica de las obras impresas en la imperial ciudad desde 1483 hasta nuestros días, Madrid, Manuel Tello, 1887; Rogers y Lapuente: P. P. Rogers, F. A. Lapuente, Diccionario de seudónimos literarios españoles, con algunas iniciales, Madrid, Gredos, 1977; Ruiz Fidalgo: Lorenzo Ruiz Fidalgo, La imprenta en Salamanca (1501-1600), Madrid, Arco/Libros, 1994, 3 volúmenes; Sánchez: Juan M. SÁnchez, Bibliografía Aragonesa del siglo XVI, Madrid, Imprenta Clásica Española, 1913-1914, 2 volúmenes; Simón Díaz, BLH: José Simón Díaz, Bibliografía de la Literatura Hispánica, Madrid, Consejo Superior de Investigaciones Científicas, 1960-1994, 2. ${ }^{\text {a }}$ ed. corregida y aumentada, 16 volúmenes; Valdenebro y Cisneros: José María VALDENEBRo y Cisneros, La imprenta en Córdoba. Ensayo bibliográfico, Madrid, Establecimiento Tipográfico Sucesores de Rivadeneyra, 1900; Whinnom: Keith Whinnom, The Spanish sentimental romance 1440-1550. A Critical Bibliography, Londres, Grant \& Cutler, 1983. 
1. Verdadero Govierno de esta Monarquia por $D^{n}$. Thomás Cerdàn de Tallada: Valencia 1581 en 16.

CERDÁN DE TALLADA, Tomás.

Verdadero gouierno desta Monarchia, tomado por su propio subiecto la conseruacion de la paz. Valencia: en casa de la viuda de Pedro de Huete. 1581. Volumen en 8. ${ }^{\circ}$.

CCPB, 5007-5.

Notas:

Palau, 51.654: recoge la obra en $4 .^{\circ}$. -Simón Díaz, $B L H, 7.845$. Teniendo en cuenta que se trata de un tratado político, resulta muy dudoso el formato en $16 .^{\circ}$. Debe tratarse de un error, ya que ese formato no se recoge en ningún repertorio bibliográfico.

2. Bueltas de escaramuza de gala à la Gineta por $D^{n}$. Bruno de Morla Melgarejo: Puerto de $S^{t a}$. Maria 1737 en $4^{o}$.

MORLA MELGAREJO, Bruno José.

Libro nuevo. Bueltas de escaramuza, de gala, a la gineta. Compuestas por Don ------. Practicadas en la plaza de la Mui Noble y Mui Leal ciudad de Xerez de la Frontera, en el año de 1737. Puerto de Santa María: Imprenta de los Gómez [s. a.].

CCPB, 1004224-5.

Notas:

Palau, 183.116: da una posible fecha (1738), tomada de la dedicatoria de la obra y añade que «los ejemplares en buen estado y completos de láminas eran ya raros en 1900». Aguilar Piñal, 5.997: ofrece la fecha de [1737]. Es probable que la fecha de publicación que aparece en el listado del marqués de la Cañada haya sido copiada directamente del título de la obra y, en consecuencia, no corresponda al año de publicación. La siguiente edición se hizo en Jerez en 1889.

3. Eneida de Virgilio por $D^{n}$. Juan Francisco de Enciso, y Moran: Cadiz 1698 en $4^{o}$.

ENCISO Y MONZON, Juan Francisco.

Traducción poética castellana de los doze libros de la Eneida de Virgilio Maron, Principe de los Poetas Latinos: Sv autor Don Jvan Francisco de Encisso Monçon, Clerigo de menores ordenes, natural de la Ciudad de el gran Puerto de Santa María. Y la consagra a la catolica Majestad de Carlos Segundo nuestro Sr. Rey de España, y Emperador de la America. Cádiz: por Cristóbal de Requena. 1698.

CCPB, 49283-3.

Notas:

Gallardo, * 2.076. -Palau, 370.506. -Simón Díaz, BLH, 4.407. 
4. Robo de Proserpina de Cayo Rusio Claudiano, por Francisco Faria: Madrid 1608 en $12^{\circ}$.

CLAUDIANO, Claudio.

Robo de Proserpina (traducido por Francisco Faria). Madrid: por Alonso Martín de Balboa, a costa de Juan Berrillo. 1608. Volumen en 8.․

CCPB, 39685-0.

Notas:

Pérez Pastor, Madrileña, 996. -Palau, 55.367: señala que tanto la primera edición (Madrid, 1608) como la segunda (Madrid, 1806) se imprimieron en volúmenes en $8 .^{\circ}$, mientras que la tercera, publicada también en 1806 por Bartolomé José Gallardo, está en 16. ${ }^{\circ}$. Por lo tanto, es probable que el formato con el que se registra la obra sea un error. -Simón Díaz, BLH, 199.

5. Poesias selectas de varios Autores Latinos, en verso Castellano, $p^{r}$. el P. Josef Morell: Tarrag ${ }^{a} 1684$ en $4^{\circ}$.

MORELL, José.

Poesias selectas de varios autores latinos. Tarragona: por José Soler, a costa de José Moya, 1684.

CCPB, 267546-3.

Notas:

Palau, 229.843, y Simón Díaz, $B L H, 2.870$ : fechan la primera edición de la obra en 1683. Según Palau, un año después un librero realizó una segunda impresión con un resto de la primera edición, en cuyo pie se leía «Impresso en Tarragona por Ioseph Soler. Año 1684. A costa de Ioseph Moya mercader de libros. Vendese en su casa en la librería». -Aguiló y Fuster no recoge la obra.

6. Epaenesis Yberica: Autore Ludovico Tribaldus de Toledo: Antuerpie 1632 in $4^{\circ}$.

TRIBALDO DE TOLEDO, Luis.

Epaenesis iberica. Antuerpiae: Officina Plantiana Balthasar Moreto, 1632.

CCPB, 381755-5.

Notas:

Debió de ser una obra rara. Peeters-Fontainas no la recoge. -Palau, 340.538: señala que «se tiene nota vaga de este poema en elogio de España en una edición madrileña también del siglo XVII». 
7. La Infanta coronada por el Rey $D^{n}$. Pedro, $D^{a}$. Inés de Castro en octava rima de $D^{n}$. Juan Suarez de Alarcón: Lisboa 1606 en $4^{o}$.

SOARES DE ALARCÓN, Juan.

La Infanta coronada, por el Rey Don Pedro, Doña Inés de Castro: en octava rima. Lisboa: Por Pedro Crasbeeck, 1606.

CCPB, 695130-9.

Notas:

Gallardo, 3.979. -Palau, 315.405.

8. Cortés valeroso, y Mexicano de Gabriel Laso dela Vega Madrid 1588 en $4^{o}$.

LASSO DE LA VEGA, Gabriel.

Primera parte de Cortes valeroso, y Mexicana. Madrid: en casa de Pedro Madrigal, 1588.

CCPB, 15016-9.

Notas:

Gallardo, 2.620: fecha la obra en 1588, aunque indica que «(Al fin.) En Madrid a dieciocho de diciembre de 1587 años». -Pérez Pastor, Madrileña, 283. -Palau, 132.558. -Simón Díaz, BLH, 5.785 .

9. Romances antiguos por Lorenzo de Sepulveda. Amberes 1566 en 16.

SEPÚLVEDA, Lorenzo de.

Romances nueuamente sacados de historias antiguas de la Cronica de España...; van añadidos muchos nunca vistos compuestos por vn cauallero Cesario, cuyo nombre se guarda para mayores cosas. Anuers: en casa de Philippo Nucio. 1566 . Volumen en $12 .^{\circ}$

CCPB, 23419-2.

Notas:

En Palau, 309.366, y Peeters-Fontainas, 1.187, aparece recogido el volumen en $12 .^{\circ}$, por lo que puede que la edición del marqués de la Cañada fuera muy rara o, simplemente, se trata de un error de la persona que elaboró el listado de la venta.

10. Carzel de Amor de Nicolás Nuñez 1500 en $8^{\circ}$.

SAN PEDRO, Diego de.

Cárcel de amor. Toledo: por maestro Pedro Hagembach aleman, 1500. Volumen en $4 .^{\circ}$.

Palau, 293.345.

Notas:

Whinnom no la registra. Gallardo y Pérez Pastor, Toledo, tampoco citan esta edición. En cuanto al formato, es probable que el volumen en $8 .^{\circ}$ sea un error de la persona que hizo el listado de libros del marqués. Palau: especifica incluso la fecha en la que se terminó de imprimir el ejemplar de 1500 «a dos días de junio», y añade que «se cita otra edición sin lugar ni año que Gayangos y Salvá suponen del siglo XV y tercera edición. Nadie la ha descrito con ejemplar a la vista». El CCPB, 22706-4: recoge un volumen [s. l., s. n., s. a.] en $4 .^{\circ}$ localizado en la Biblioteca Nacional de Madrid, que puede corresponder al mencionado anteriormente por Palau. 


\section{Reinaldos de Montalvan. Alcalá 1563 en folio.}

Libro primero de don Renaldos. [Traducción Luis Domínguez]. Alcalá de Henares: En casa de Sebastián Martínez; a costa de Luys Gutiérrez librero vezino de Alcalá y de Miguel Ferrer impressor de libros vezino de Toledo, 1563.

Martín Abad, 567.

Notas:

Gallardo, 1.077. -Palau, 260.920. -Simón Díaz, BLH, 7.505. Lucía Megías, pág. 605, precisa que este volumen incluye en realidad los libros I y II de la obra. -Para Gayangos, pág. LXVI, la primera parte se publicó de manera independiente en 1563, aunque a continuación señala que la publicación de «las dos partes en un tomo» apareció en 1564. En 1563 también apareció en Alcalá el tercer libro, conocido como La Trapesonda, que recogen Martín Abad, 587, y Lucía Megías, pág. 606. Tal como está registrada la obra en el listado, sin indicar que se trate del tercer libro ni citarla con su sobrenombre, puede entenderse que el título hace alusión a los dos primeros libros.

\section{Amadis de Gaula, corregido p. GarciOrdoñez de Montalvo Salamanca 1575} en fol.

Aqui comieçan los quatro libros primeros del inuencible caualleo Amadis de Gaula: en los quales se tratan sus altos hechos de armas y cauallerias: nueuamente impresos. Salamanca: Pedro Lasso, a costa de Lucas de Junta, 1575.

CCPB, 348612-5.

Notas:

Hubo dos emisiones salmantinas de la obra realizadas por el mismo impresor en el mismo año aunque financiadas por personas diferentes. Dado que el listado no especifica a cuál de las dos se refiere, mencionamos la edición a costa de Lucas de Junta por ser la más difundida entre los distintos repertorios bibliográficos actuales. Ruiz Fidalgo, 898A. Lucía Megías, pág. 598. -Ruiz Fidalgo, 898B: recoge la otra edición que se hizo en Salamanca ese mismo año a «costa de Vincenzo de Portonarijs». Lucía Megías no registra esta última emisión, aunque sí cita la realizada por Alonso de la Barrera a costa de Francisco de Cisneros (Sevilla, 1575). Gayangos, pág. LXVII: cita las dos emisiones.

\section{El ramo que de los quatro Libros de Amadis de Gaula sale llam ${ }^{\text {do }}$. los del mui} esforzado Cavallero Esplandian, hijo del otro Amadis. Alcalá 1588 en fol.

RODRÍGUEZ DE MONTALVO, Garci.

El ramo que de los quatro libros de Amadis de Gaula sale, llamado las Sergas del muy Esforçado Cauallero Esplandian, hijo del excelente Rey Amadis de Gaula... Alcalá de Henares: por los herederos de Juan Gracián, 1588.

CCPB, 687422-3.

Notas:

Lucía Megías, pág. 598, y Martín Abad, 1.005: recogen esta edición. Gayangos, pág. LXVIII: añade que es «sin duda la misma que Salvá, en el Repertorio Americano, página 33, pone como hecha por los herederos de Juan de Garay». 


\section{Palmerin de Oliva 1580 fol.}

Palmerin de Oliua. Libro del famoso cauallero Palmerin de Oliua, que por el mundo grandes hechos en armas hizo, sin saber cuyo hijo fuesse. Toledo: Pedro López de Haro, 1580.

CCPB, 19652-5.

Nota:

Gayangos, pág. LXXI, y Lucía Megías, pág. 605: registran esta edición. -Pérez Pastor, 357: señala que «no se encuentran en esta edición los dísticos latinos de Joan de Auger» que sí aparecen en otras ediciones.

15. Memorial de cosas notables por Dn. Iñigo Lopez de Mendoza Guadalaxara 1504 fol.

LÓPEZ DE MENDOZA, Íñigo, duque del Infantado.

Memorial de cosas notables. Guadalajara: por Pedro de Robles y Francisco de Cormellas, 1564.

CCPB, 13630-1.

Notas:

Gallardo, 2.770, Simón Díaz, BLH, 3.289, y Palau, 1.458: indican que la primera edición de la obra apareció en 1564, por lo que la fecha del listado de los libros es claramente un error. El marqués de la Cañada tuvo el volumen que registran ambos repertorios bibliográficos. Catalina García no cita esta obra.

16. Vida de $S^{n}$. Hermenegildo, por $D^{n}$. Manuel Lopez, Ponze de Salas, Presbítero. Madrid 1680 en $4^{\circ}$.

LÓPEZ PONCE DE SALAS, Manuel Francisco.

Vida de San Hermenegildo rey y martyr de Espana... Madrid: Bernardo de Villa-Diego, 1680.

CCPB, 52667-3.

Notas:

Palau, 141.835. -Simón Díaz, BLH, 3.411.

17. Soberanía del Reyno de España, por $D^{n}$. Alonso Carrillo Laso Cordova 1626 en $4^{\circ}$.

CARRILLO LASSO, Alonso.

Soberania del Reyno de España. Cordoua: Salvador de Cea Tesa, 1626.

CCPB, 40036-X.

Notas:

Gallardo, 1.616. -Simón Díaz, BLH, 5.424. -Palau, 45.589. -Valdenebro y Cisneros, 127. 
18. Retrato Político del Rey $D^{n}$. Alonso $8^{o}$ por $D^{n}$. Gaspar Mercader. Valencia 1679 en $4^{\circ}$.

MERCADER Y CERVELLÓ, Gaspar, conde de Cerbellón.

Retrato politico del señor Rey D. Alfonso el VIII que dedica a la S.C.R.M. del Rey... Don Carlos II. Valencia: por Francisco Mestre, 1679.

CCPB, 33397-2.

Notas:

Simón Díaz, BLH, 5.422. -Palau, 164.945: indica que «corre otra edición contrahecha de Valencia, por Francisco Mestre, junto al Molino de la Rovella, Anno MDCLXXIX (1679), $4^{\circ}{ }^{\circ}$.

19. Historia de Astorga, por Dn. Pedro Junco 1639 en $4^{o}$.

JUNCO, Pedro de.

Fundación, nombres, y armas de la ciudad de Astorga. Pamplona: por Martin de Labayen. 1639 (En Madrid: por Pedro Laso mercadel [sic] de libros).

CCPB, 173399-0.

Notas:

Simón Díaz, BLH, 5.097. -Palau, 126.106: especifica que se trata de la segunda impresión de la obra, en cuya anteportada se lee «En Madrid, por Pedro Lasso, mercader de libros. Año 1639». Moreno Garbayo, 1.952: corrobora estos datos.

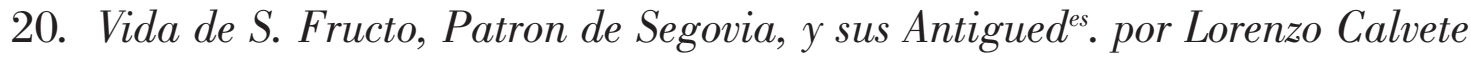
1610 en $12^{\circ}$.

ORCHE, Juan de.

Historia de la vida del glorioso S. Fructos patron de la ciudad de Segovia, y de sus hermanos San Valentin y Santa Engracia: contiene la destruycion de España por los moros, grandezas y antiguallas de la ciudad de Segovia con un compendio de los Reyes y Reynas que han Reynado en España desde que la comenzaron a ganar y restaurar de los Moros... Valladolid: por Cristóbal Lasso Vaca, 1610. Volumen en 8. .

CCPB, 210824-0.

Notas:

El volumen recogido por Gallardo, 1.541, y Palau, 202.205, también está en $8 .^{\circ}$, por lo que resulta poco probable que el marqués de la Cañada tuviera un volumen en $12 .^{\circ}$. Palau afirma que Lorenzo Calvete, el nombre que aparece en la portada, se corresponde con el del hermano del autor, ya que al unir las iniciales de las octavas que figuran en los preliminares de la obra se lee: «El Padre Frai Ivan de Orche escribió esta hystoria el año de myl y seyscientos y nueve en su casa del Parral de Segovia». Para P. P. Rogers y F. A. Lapuente, Diccionario de seudónimos literarios españoles, con algunas iniciales, pág. 105, Lorenzo Calvete es el seudónimo de Juan de Orche. En cualquier caso, el autor que aparece en el listado de los libros del marqués proviene de la portada. 


\section{Historia de Carmona pr. Fr. Juan Salvador, Sevilla 1628 en $12^{\circ}$.}

ARELLANO, Juan Salvador Bautista.

Antigüedades y excelencias de la villa de Carmona, y compendio de historias. Sevilla: por Simón Fajardo. 1628. En 8. .

CCPB, 32807-3.

Notas:

Escudero, 1.397. -Simón Díaz, BLH, 4.069. El volumen que registra Palau, 15.853, también está en $8 .^{\circ}$, por lo que resulta poco probable que el marqués de la Cañada contase con un volumen en 12. ${ }^{\circ}$. Palau añade una valoración de la obra: «Muñoz y Romero dice que esta obra es floja, pues se funda en los falsos cronicones de Dextro, y en las tradiciones vulgares».

\section{Executoria y Privilegios de Medina Sidonia 1602 en $4^{o}$.}

SÁNCHEZ DE HERRERA, Juan.

Privilegios de la Ciu(da)d de Medina Sidonia según se hallan en un Códice q(u)e (...) contiene una executoria librada por la R(ea)l Chanz(illerí)a de Granada a favor de dicha Ciu(da)d en pleito q(u)e tubo con el Duque de su titulo, el de Medinaceli, y los Concejos de la V(ill)a de Ximena, Puerto de S(an)ta María y el Duque de Alcalá, Marq(ue)s de Tarifa, y las ciudades de Xerez de la Frontera, Cádiz, Ronda, Arcos, Sanlucar de Barrameda, Chiclana, Bejer, Conil, Tarifa, Casares, y los Molares, Lazerna, Carmona, Puerto R(ea)l, Bornos, Utrera y Lebrija (....). [s. l.], 1602.

Notas:

Para los datos del manuscrito nos hemos basado en la descripción realizada por Juan Manuel Abascal Palazón y Rosario Cebrián Fernández en Manuscritos sobre antigüedades de la Real Academia de la Historia, Madrid, 2006, págs. 82-83, referencia 9-8073-6.

\section{Historia de Calatayud, $p^{r}$ Miguel Martinez del Villar 1598 en $4^{\circ}$.}

MARTÍNEZ DEL VILLAR, Miguel.

Tratado del Patronado, antiguedades, gouierno y varones illustres de la ciudad y Comunidad de Calatayud y su Arcedianado: donde tambien se trata de las grandezas de los reyes y reynos de Aragon y de la excelencia de su fidelidad, todos los patronados de España, diezmos y primicias que gozan el Rey Nuestro Señor, ricos hombres, ciudades, villas y lugares della...; va al fin vn indice copioso. Çaragoça: por Lorenço de Robles, 1598.

CCPB, 17167-0.

Notas:

Sánchez, 825. -Palau, 156.232: señala que se trata de la primera parte de una «obra bien trabajada y digna de consulta», cuya continuación tuvo preparada el autor, aunque permaneció inédita. -Simón Díaz, BLH, 3.094. 


\section{Historia de Cataluña de Jerónimo Pujades 1609 fol en Catalan.}

PUJADES, Jerónimo.

Coronica universal del Principat de Cathalunya... Barcelona: en casa de Hieronym Margarit, 1609.

Palau, 241872.

Notas:

Aguiló y Fuster, 2826. -Palau especifica que ésta es sólo la primera parte de la obra, la cual «es muy apreciada».

25. Crisis de Cataluña pr las Naciones extrangeras del P. Manuel Marcilio 1685 en $4^{\circ}$.

MARCILLO, Manuel.

Crisis de Cataluña hecha por las naciones estrangeras. Barcelona: Jaime Mathevat, 1685.

CCPB, 33315-8.

Notas:

Aguiló y Fuster no cita la obra. -Palau, 151.149: añade que se trata de una «obra estimada y de interés para la Historia de Cataluña».-Simón Díaz, BLH, 1.067.

26. Historia de Gerona pr Fr. Juan Roig 1678 Fol $^{\circ}$.

ROIG I SALPÍ, Joan Gaspar.

Resumen historial de las grandezas y antiguedades de la Ciudad de Gerona : y cosas memorables suyas Eclesiasticas y seculares..., vida, martyrio... de San Narciso... y defensa de la entrada de Carlos el Grande en Cataluña en una carta apologetica... Barcelona: por Iacinto Andreu, 1678.

CCPB, 38774-6.

Notas:

Aguiló y Fuster no la menciona. -Palau, 275.562: apunta que es «una de las mejores obras antiguas sobre la historia de Gerona» y registra el nombre del autor con una ligera variación: «Joan Gaspar Roig y Gelpi».

27. De la $S^{t a}$. Cruz, y Antigüedades de Tortosa $p^{r}$ Francisco Martorel 1726 en $12^{\circ}$.

MARTOREL Y DE LUNA, Francisco.

Historia de la Santa Cinta con que la Madre de Dios honrò la Catedral, y ciudad de Tortosa: del sitio, nombre, antiguedad, obispado, y cosas notables della: con variedad de historia, y una descripcion de Cataluña, y su fidelidad. Tortosa: Geronimo Gil, 1626. Volumen en 8. . CCPB, 205968-1.

Notas:

Palau, 156.486, y Simón Díaz, BLH, 3.158: fechan la obra en 1626, por lo que el año que aparece en el listado de los libros del marqués es seguramente un error. En cuanto al formato del volumen, debe tratarse de otro error, porque los repertorios bibliográficos consultados registran el volumen en 8. ${ }^{\circ}$. Palau señala que fue una obra rara, pero de valor, aunque «el autor, llevado por el excesivo amor a su patria, da acogida en su obra a los falsos cronicones, y la historia primitiva carece de documentos verídicos». 


\section{Historia de Tortosa $p^{r} d^{n}$. Vizente Mirabal, y Forcadell, 1641 en $4^{o}$.}

MIRAVALL Y FLORCADELL, Vicente de.

Tortosa ciudad fidelissima y exemplar: motivos que el rey... Felipe el Grande, quarto de Castilla... ha tenido para concederla estos gloriosos títulos, en premio de la lealtad que ha mostrado en las alteraciones de Cataluña... Madrid: Imprenta del Reyno, a costa de Tomás Alfay, 1641.

CCPB, 33435-9.

Notas:

Palau, 172.333: añade que «salen poco en el comercio los ejemplares de esta obra», por lo que podemos entender que se trata de un volumen raro. -Simón Díaz, BLH, 633. -Moreno Garbayo, 2329.

29. Historia de Asturias $p^{r}$ el P. Luis Carballo 1695 Fol $^{\circ}$.

CARVALLO, Luis Alfonso de.

Antigüedades y cosas memorables del principado de Asturias. Madrid: por Julián de Paredes, 1695.

CCPB, 39986-8.

Notas:

Palau, 46.633. -Simón Díaz, BLH, 566.

30. Asturias ilustrada $p^{r}$ Trelles 1736 fol. 2 tom $^{\text {s. }}$

TRELLES VILLADEMOROS, José Manuel.

Asturias ilustrada: origen de la nobleza de España, su antigüedad, y diferencias: dividida en tres tomos: tomo primero. Madrid: Joachin Sánchez, 1736.

CCPB, 60800-9.

Notas:

El CCPB, 65081-1: recoge el segundo tomo de la obra, publicado en Madrid en 1739. Aguilar Piñal, 1.166: especifica que el tercero no llegó a publicarse. Cada una de las partes editadas constituía un solo tomo. Dado que el listado registra dos tomos, podemos asegurar que el marqués de la Cañada tuvo ambas partes de la obra, aunque sólo se cite la fecha de publicación del primer tomo. -Palau, 340.110: valora ambas partes, aunque considera que están basadas en falsos cronicones. Por eso, prefiere la edición aumentada posterior: «Historia chronologica y genealogica del primitivo origen de la Nobleza de España, su antigüedad, clases y diferencias, con sucesiones continuadas de las principales familias del Reyno, y con la ilustración del Principado de Asturias..., Madrid, Domingo Fernández de Arrojo, 1760, 4으, 4 tomos en 8 volúmenes». 
31. Descripción del Sepulcro de Saturnino, hallado en Merida año 1650, según Garcia Salzedo Coronel, en $4^{\circ}$.

SALCEDO CORONEL, José García de.

Inscipcion del sepulcro de Saturnino penitente: que se hallo en la ciudad de Merida año de MDCL. [S.l.]: [s. n.], [s. a.].

CCPB, 432982-1.

Notas:

Gallardo, 3.790. -Palau, 287.010: la fecha en 1650.

32. Nobiliario de Casas, y Linages de España pr Fr. Thomás de Llano 1653 en $4^{\circ}$.

LLANO, Tomás de.

Noviliario de casas y linages de España. [Valladolid ?]: [s. n.], 1653.

CCPB, 34185-1.

Notas:

Alcocer, 873, y Marsá, 1.456: corroboran el lugar de impresión.

33. Ricos hombres, è Ynfanzones de Aragon $p^{r} D^{n}$. Juan de Montem ${ }^{r}$ y Cuenca 1645 en $4^{\circ}$.

MONTEMAYOR Y CÓRDOBA DE CUENCA, Juan Francisco de.

Summaria investigacion de el origen y privilegios de los ricos hombres o nobles, caballeros, infanzones o hijos dalgo, y señores de vassallos de Aragon, y del absoluto poder que en ellos tienen: parte primera. [S. l.: s. n., s.a.].

CCPB, 37162-9.

Notas:

Palau, 178.029: fecha la obra en 1664 y da México como el lugar de su publicación y señala que hay ejemplares en cuyos preliminares se fecha la obra «en México, 25 febrero 1665». -Simón Díaz, BLH, 2.016: aporta los mismos datos (México, 1664). En cualquier caso, podemos pensar que el año de publicación con el que se registra la obra en el listado es erróneo. Según Palau, este volumen se corresponde únicamente con la primera parte de la obra, que fue muy cotizada. La segunda parte no llegó a publicarse nunca. 
34. Seneca Juez de si mismo en la Causa que litigan Dn. Alonso Nuñez de Castro, Dn. Diego Ramirez de Albeada, y dn. Juan Baños de Velazco pr Fr. Franco. de Sarraga, Burgos 1685 en $4^{o}$.

ZARRAGA, Francisco.

Seneca iveg de si mismo, impugnado, defendido, y ilustrado en la causa política y moral que litigan Don Alonso Nuñez de Castro, Don Diego Ramirez de Albelda y Don Iuan de Baños de Velasco y Azeuedo... - Segunda impresion. Burgos: por Iuan de Viar y a su costa, 1685 (1684).

CCPB, 56310-2.

Notas:

Palau, 379.789: sólo cita la edición burgalesa que hizo Juan de Viar en 1684. Sin embargo, el CCPB especifica que la edición de 1684 sirvió de base para la realizada supuestamente al año siguiente.

\section{Cronica de los nueve de la Fama 1532 Fol.}

Cronica llamada el triunfo de los nueue mas preciados varones de la fama... Traduzida en nuestro vulgar castellano y agora nueuamente reprimida, corregida y enmendada ... Valencia: Iuan Nauarro, 1532.

CCPB, 422996-7.

Notas:

Gayangos, pág. LXXXv: cita la obra y localiza un ejemplar en la «Biblioteca Imperial de Viena». Lucía Megías no lo menciona.

36. Declara ${ }^{n}$ de las Monedas encontradas en el Alcazar de Gran ${ }^{a}$. $1624 p^{r}$. Mig ${ }^{l}$ de Bergara 1633 en $4^{\circ}$.

VERGARA GAVIRA, Miguel de.

Verdadera declaracion de las monedas antiguas que se han hallado en vn edificio antiguo que se ha descubierto debaxo de tierra en el Alcazaua de Granada, por Febrero deste año de 1624. Madrid: por Iuan Gonçalez, 1624. Volumen en folio.

CCPB, 48810-0.

Notas:

El CCPB, 614049-1: recoge otra edición del mismo año, pero publicada en Granada en $4 .{ }^{\circ}$, que no aparece en López-Huertas. -Palau, 360.148: cita sólo la edición de Madrid. -Pérez Pastor, Bibliogr. Madrileña, III, 2.139: también registra la edición. Teniendo en cuenta esto, hemos preferido identificar la referencia del listado del marqués con la edición madrileña, a pesar de que el formato que aparece $\left(4 .^{\circ}\right)$ coincide con la edición granadina. En cuanto al año de edición (1633), consideramos poco fiable dicho dato, ya que no aparece en ningún repertorio bibliográfico. No obstante, también es posible que pueda tratarse de un error de la persona que hizo el catálogo de los libros. 